\title{
Industry 4.0: Revolution or Evolution?
}

\author{
Elnaz Asadollahi-Yazdi1,2, Paulin Couzon ${ }^{1,2}$, Nhan Quy Nguyen",2, Yassine Ouazene ${ }^{1,2}$, \\ Farouk Yalaoui ${ }^{1,2}$
}

${ }^{1}$ Chaire Connected Innovation, Université de Technologie de Troyes, Troyes, France

${ }^{2}$ ICD-LOSI, Université de Technologie de Troyes, Troyes, France

Email: elnaz.asadollahiyazdi@utt.fr

How to cite this paper: Asadollahi-Yazdi, E., Couzon, P., Nguyen, N.Q., Ouazene, Y. and Yalaoui, F. (2020) Industry 4.0: Revolution or Evolution? American Journal of Operations Research, 10, 241-268.

https://doi.org/10.4236/ajor.2020.106014

Received: August 31, 2020

Accepted: October 12, 2020

Published: October 15, 2020

Copyright $\odot 2020$ by author(s) and Scientific Research Publishing Inc. This work is licensed under the Creative Commons Attribution International License (CC BY 4.0).

http://creativecommons.org/licenses/by/4.0/

\begin{abstract}
"Industry 4.0" term is devoted to the fourth industrial revolution. Over time and by developing different technologies, this term is coming with the new paradigm and technologies, which help to connect the machines, products, and methods as an interconnected system. This paper aims to introduce an analysis and a reflection around the concepts industry 4.0 and their impacts in the actual industrial world. The effects of this digitalization will be investigated on supply chain systems, decision-making processes, and business models. The classic supply chain is evolving into a Network Supply System (NSS) that is an interconnected supply chain with more focus on product and customer expectations. The global value chain process tends to be product-oriented. Smart data make the decisions more dynamic, flexible, and precise. Therefore, every industrial sector has to be adapted to this digital transformation in all aspects. However, the environmental aspects, global warming, and human healthcare issues are the challenge facing industries and human life, which can be like a brake to make efforts to improve digital life and machine technicity. This paper tries to produce a critical analysis of the concept "industry 4.0 revolution" based on different guidelines to show that it is an evolution of the industry coming through the development of several technologies.
\end{abstract}

\section{Keywords}

Industry 4.0, Supply Chain 4.0, Value Chain, Effort and Value, Network Supply System, Decision-Making, Digital Maturity

\section{Introduction}

The industrialization process began with the introduction of mechanical manufacturing equipment at the end of the 18th century. The development of the 
steam engine by James Watt permits revolutionizing the way products are made by machines and engines. Besides, agricultural society transformed into an industrial society. Until now, four industrial revolutions happened as shown in Figure 1. The first industrial revolution made tremendous improvements by mechanization, steam energy, and weaving loom. This transformation was followed by a second industrial revolution at the beginning of the 20th century and involved mass production, assembly line, and electrical energy. This revolution implied organizational changes, such as the implementation of Henry Ford's assembly line and the scientific management procedures based on Frederic W. Taylor, better known as Taylorism. In this revolution, mass production as large-scale industrial manufacturing raised. Therefore, the chemical and electronics industry, as well as the mechanical engineering and automotive industry took advantage of these revolutions and started growing [1].

During the early 1970s, the third industrial revolution has emerged and it is continuing right up to the present day. Implementation of electronics and information technology are the best characteristics of this revolution that increased automation of manufacturing processes, as well as replacing the machines instead of laborers. Hence, it creates socio-economic and socio-cultural effects. Moreover, versatile serial production increased the productivity of manufacturing processes. Nowadays, the third revolution is still present but it is smoothly transforming into a new age of industrialization known as the fourth industrial revolution (Industry 4.0) [2].

On the other hand, market demand and society needs are the main drivers for the development of industrial automation [4] [5]. Over the past centuries, the way that industrial automation applies to manufacture has been experiencing multiple paradigm shifts according to the market demand and society needs [4] [5]. Figure 2 illustrates this fact and we can summarize it as follows [4] [6]:

- Craft Production: The craft production is defined as the production of the exact product the customers asked for. Until the mid of the 20th century, this production prevailed and the utilization of automated equipment was limited to simple general-purpose machines. Due to increasing market demand and

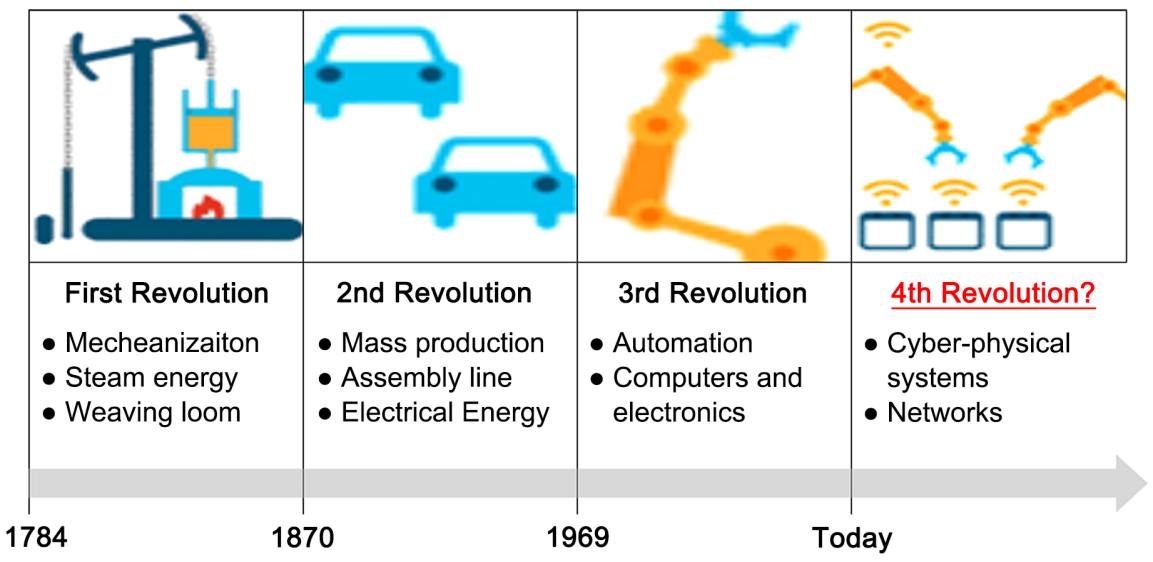

Figure 1. Industrial Revolutions-inspired from study of Horvath in 2018 [3]. 


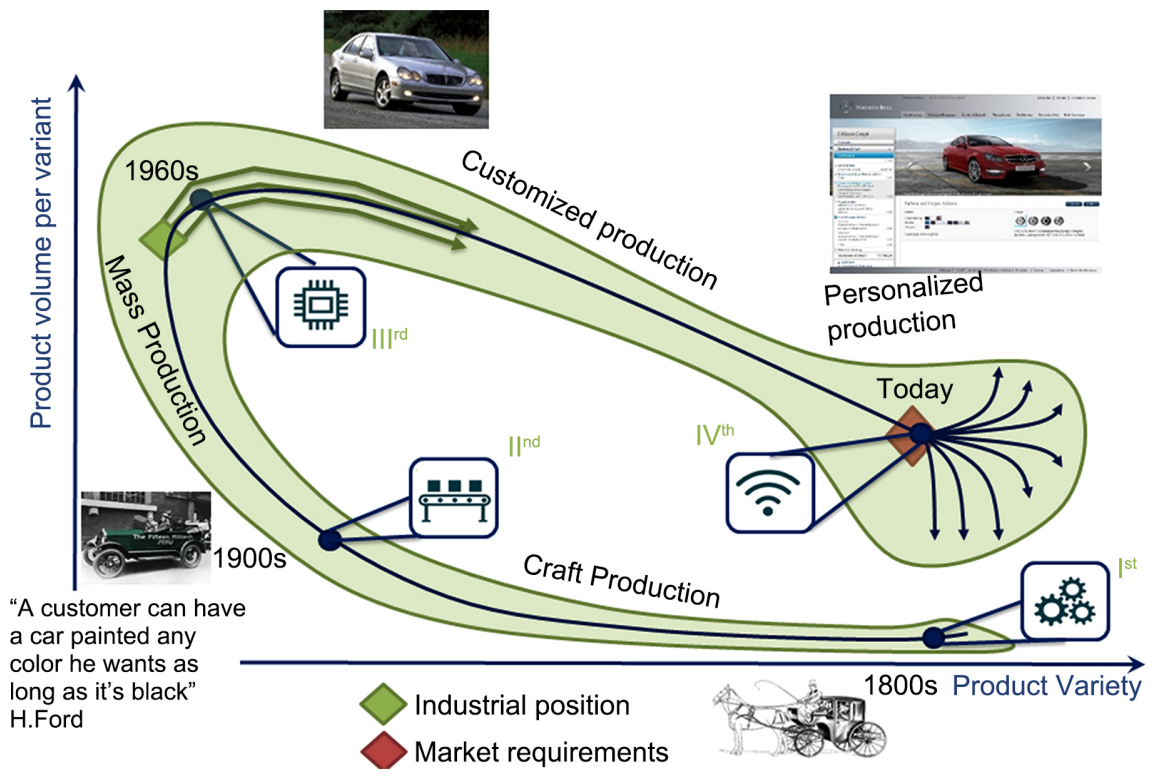

Figure 2. Paradigm shifts in manufacturing over the past centuries (adapted from the study of Koren in 2010 [4]).

for achieving high production volumes, fully automated tasks were required to replace human workers. Dedicated Manufacturing Lines (DMLs) were used for this purpose, which was only capable of producing a single product without variation.

- Mass production: Mass production started when production systems were capable of producing a single product without variation. Mass production tackled with decreased product variety, as well as reduced cost of the goods.

- Customized production: At the end of the 20th century, by increasing the societal demand for customized goods and product variety while increasing production volume slightly, the era of mass production started. During this era, the production systems need to be automated in order to maintain the low production cost of mass production while increasing its flexibility. Hence, Flexible Manufacturing Systems (FMSs) were designed to tolerate the variance introduced by customization (e.g., Computerized Numerical Control (CNC) machines).

- Personalized production: In the 21st century, globalization creates extreme competition and a higher volume of available products on the market due to the regionalization. Therefore, a trend towards differentiation based on the personalization of products arose. Re-configurable Manufacturing Systems (RMSs) has been presented to encounter with this personalization. These systems are designed in a modular way and they can be reconfigured and upgraded quickly, that concern hardware and software.

Koren [4] summarizes the paradigm shifts mentioned above as follows (Figure 2):

"Over the past two centuries, manufacturing has come nearly full circle: From focusing on the individual (Craft) to focusing on the product (Mass Production), 
to focusing on targeted market groups (Customization), and back to the individual customer (Personalization).”

To encounter these transformations, revolution or evolution, companies must be agile enough to remain in this competitive industrial world. Interbrand ${ }^{1}$, a global brand consultancy, presents an annual ranking of the best global brand based on its brand value. As illustrated in Figure 3, inspired by the Interbrand rankings of 2000 and 2019, the huge companies that were the leaders in 2000 like IBM, Intel, and General Electric, lose their rank over time. In addition, there are brands like Nokia, AT\&T that have disappeared in this ranking. The technological group of Microsoft, Coca-Cola, and McDonald in the food industry, as well as Disney in the media sector, remained in this classification. Moreover, the strong entrance of Apple, Google, Amazon, and Samsung in technological sectors, as well as, Toyota and Benz in the automotive sectors is remarkable in this ranking. Therefore, companies must be sensitive to all the modifications and transformations to remain in this competitive industrial world.

Industry 4.0 has received remarkable attention from the business and research community. This idea is not new and was on the agenda of academic research in many years with different perceptions, the term "Industry 4.0 " modifies not only academic life but also industrial society [8].

Now the question is industry 4.0 a revolution or a simple evolution? Presenting this question helps us to find that industry 4.0 is a revolution or it is just an evolution in the industrial world that emerged by developing the different technologies. This paper tries to produce a critical analysis of the concept "industry 4.0 revolution" based on different guidelines to show that it is an evolution of the industry coming by technology improvement.

In the industry 4.0 era, all the companies tend to be compatible with industry 4.0 concepts and pillars to remain in the competitive industrial world. All the companies must be familiar with industry 4.0 aspects and adapt their supply chain system, and decision making approaches to its features. Therefore, this study aims to answer these following questions that help companies and researchers in their transition:

- What do we know about industry 4.0?

- Can we represent the value chain and supply chain?

- Is decision-making sensitive to digital transformation?

- What will happen in the business world? (What's next?)

Therefore, the remainder of this paper is organized as follows. Industry 4.0 and its concepts will be discussed in the next section. Section 3 is devoted to the evaluation of the value chain and supply chain in industry 4.0 systems. Section 4 discusses the decision making approaches and their transformations in this digital world. In addition, business models and the effect of industry 4.0 in the business world will be presented in Section 5. Section 6 presented a discussion about the actual level of digitalization and in near future. Finally, Section 7 concludes with a summary.

${ }^{1}$ https://www.interbrand.com 


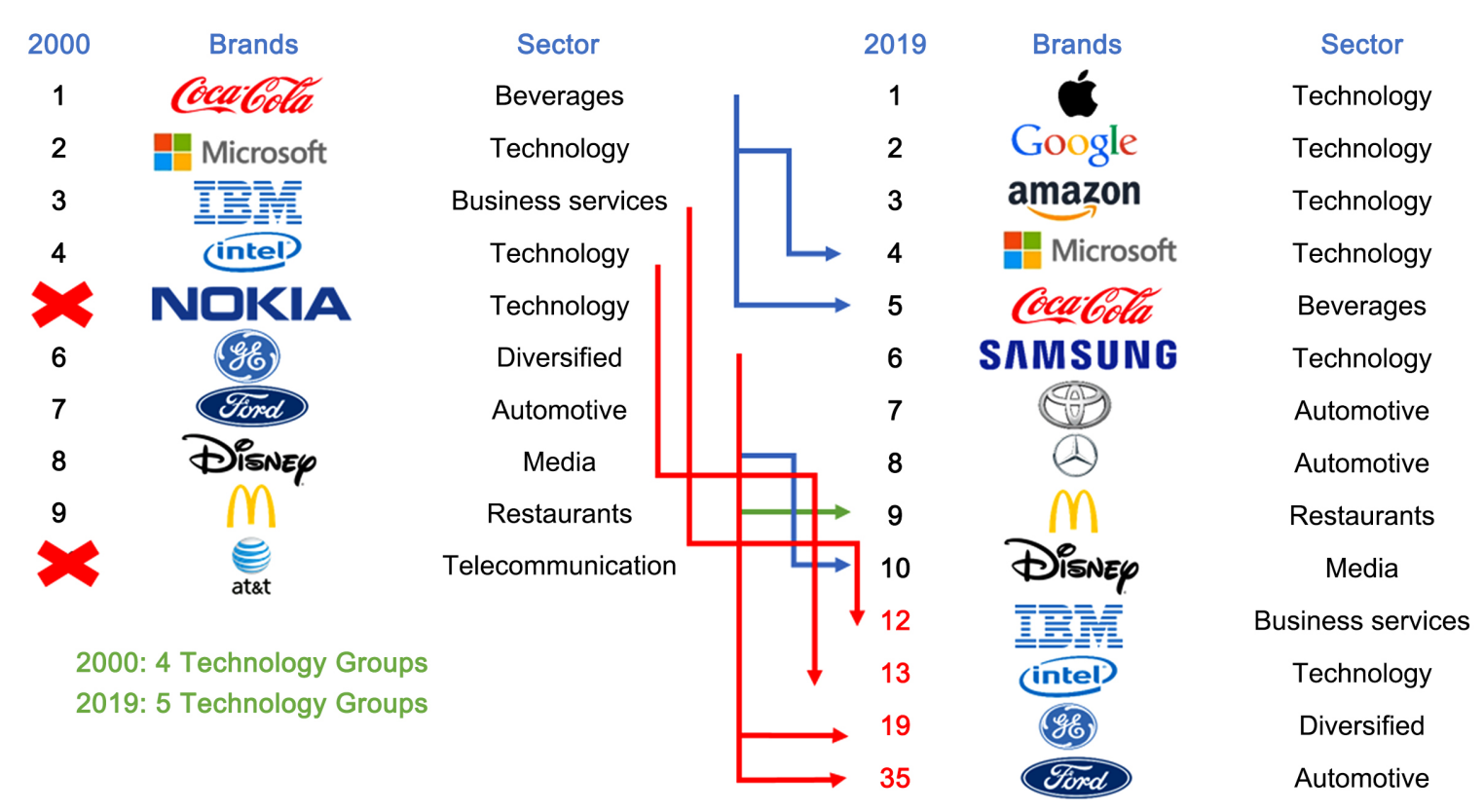

Figure 3. The global brands with most values-inspired by the analysis of Interbrand [7].

\section{Industry 4.0}

Industry 4.0 is an interconnected system, connecting machines, methods, and products. According to Deloitte Analysis [9], the five key characteristics of smart factories (as shown in Figure 4) are:

- Connected: Real-time data by using sensors and location-based database make the decision-making more precise. In these systems, processes, machines, and humans are connected.

- Optimized: Reliable, increased up-time assets and productivity, highly automated with minimal human interaction, as well as minimizing the production and quality cost create an optimized system.

- Transparent: Complete visibility of customer demand forecasts, order tracking, and other live metrics that allow real-time decision-making.

- Proactive: Constant evaluation of stock, and active replenishment policy, early identification of supplier quality issues, and real-time safety monitoring.

- Agile: Adaptable scheduling changeovers, implementation of product changes in real-time, as well as configurable factory layouts and equipment.

All these key features play a crucial role in the fourth revolution of the industry enabling the decision-maker to be informed and improving the production process and global organization.

As illustrated in Figure 5, nine technologies create the foundation for industry 4.0. Many of these technologies are already used in manufacturing, but with industry 4.0, they will transform into the production process as an optimized cells that will come together as a fully integrated, automated, and optimized production flow. They increase efficiency and change the traditional supply chain system, as well as the relationship between humans and machines. These nine pillars are explaining as follow [10]: 


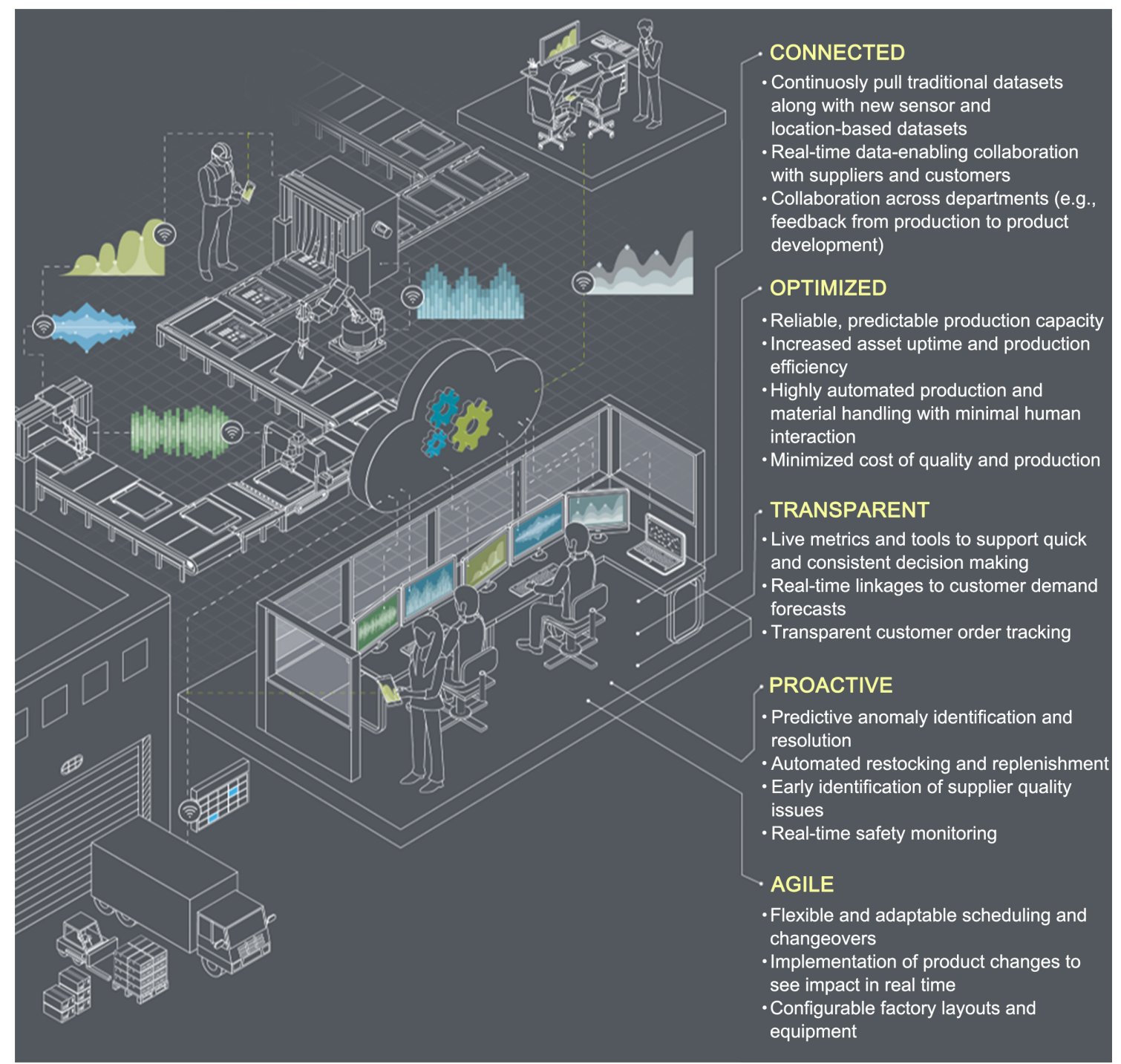

Figure 4. Industry 4.0 key features [9].

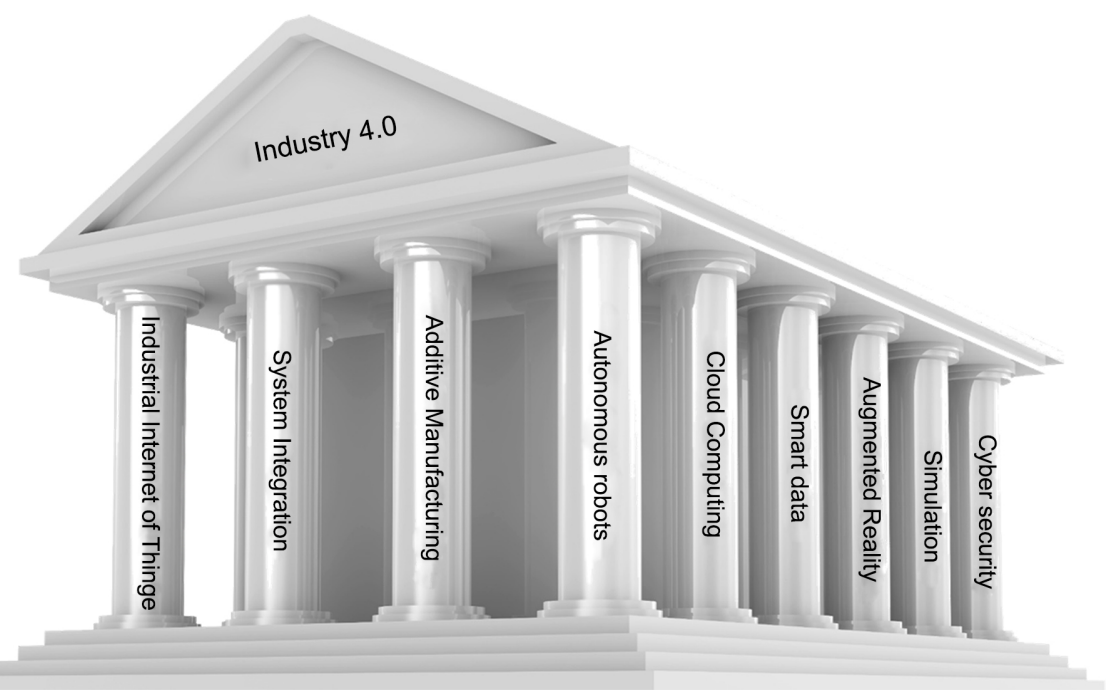

Figure 5. The nine main pillars of industry 4.0 . 
- Industrial Internet of Things (IIoT or IoT): IoT integrates sensors into the manufacturing system. Manufacturer's sensors and machines are networked and make use of embedded computing. It creates the possibility to collect and analyze data in a decentralized manner.

- System Integration: In industry 4.0, companies, departments, functions, and capabilities will become much more cohesive, as cross-company. Therefore, this cross-company, as well as universal data-integration networks evolve and enable truly automated value chains. Therefore, it creates connectivity within the supply chain, between suppliers and customers through vertical and horizontal integration.

- Additive Manufacturing: Additive Manufacturing (AM) or 3D printing is used to produce small batches of customized production. It creates advantages including producing complex products and lightweight structures [11]. This high-performance and decentralized AM systems will reduce transport distances and stock on hand. Therefore, it modifies the supply chain system.

- Autonomous robots: Nowadays, robots are used to tackle complex tasks and collaborate with each other and with humans. These robots are autonomous, flexible, and cooperative. Moreover, they cost less and have a greater range of capabilities than those used in manufacturing today.

- Cloud Computing: Cloud-based software is used by companies to increase data storage capability and allow easier communication with different stakeholders (resources, suppliers, and customers).

- Smart data: Analytic based on large data sets has emerged in the manufacturing world as a way to optimize production quality, save energy, and improve equipment service. It is devoted to the analysis of a huge amount of collected data and providing real-time decision-making.

- Augmented Reality: Augmented-reality-based systems support a variety of services, such as selecting parts in a warehouse and sending repair instructions over mobile devices. It provides real-time information to help manufacturers in real-time decision-making and improving work processes.

- Simulation: 2D or 3D simulation of product development, material development, and production processes were already used in the industrial world. Nowadays, simulations have to be used more extensively in plant operations. These simulations provide real-time data to mirror the physical world in a virtual model, including machines, products, and humans. It creates an opportunity to test and optimize the machine settings for the next in-process product in the virtual world before entering to physical phase. Hence, it decreases the machine setup times and increases production quality.

- Cyber Security: Industry 4.0 increases the connectivity and the use of standard communications protocols. It is then necessary to protect information systems, industrial systems, manufacturing lines, and equipment from cyber-security threats, whose frequency is increasing dramatically. It is essential to create secure, reliable communication, as well as sophisticated identity and 
access management of machines and users.

Industry 4.0 and its 9 pillars provide numerous benefits for the industrial world including (see Figure 6) [12]:

1) Productivity: People and machines can establish a smart working relationship thus allowing businesses to increase production capacity, reduce human errors, and offer mass customization to meet diversified needs within short notice.

2) Agility: Improved agility helps an organization to replace an existing product by a customer-based product and speeds up product innovation.

3) Innovation: The extreme visibility from IoT feeds at intelligent products and equipment to enable a better understanding of what works for both product and process design.

4) Customer Experience: Data from Manufacturing Execution System (MES) can be a basis to resolve immediately the issues between customers and manufacturers.

5) Cost: While industry 4.0 requires initial investments, once the intelligence is built into products and processes, the costs plummet. Fewer quality problems lead to less material waste, less staff, and lower operating costs. The speed and ability to handle such a high mix seamlessly also reduce costs.

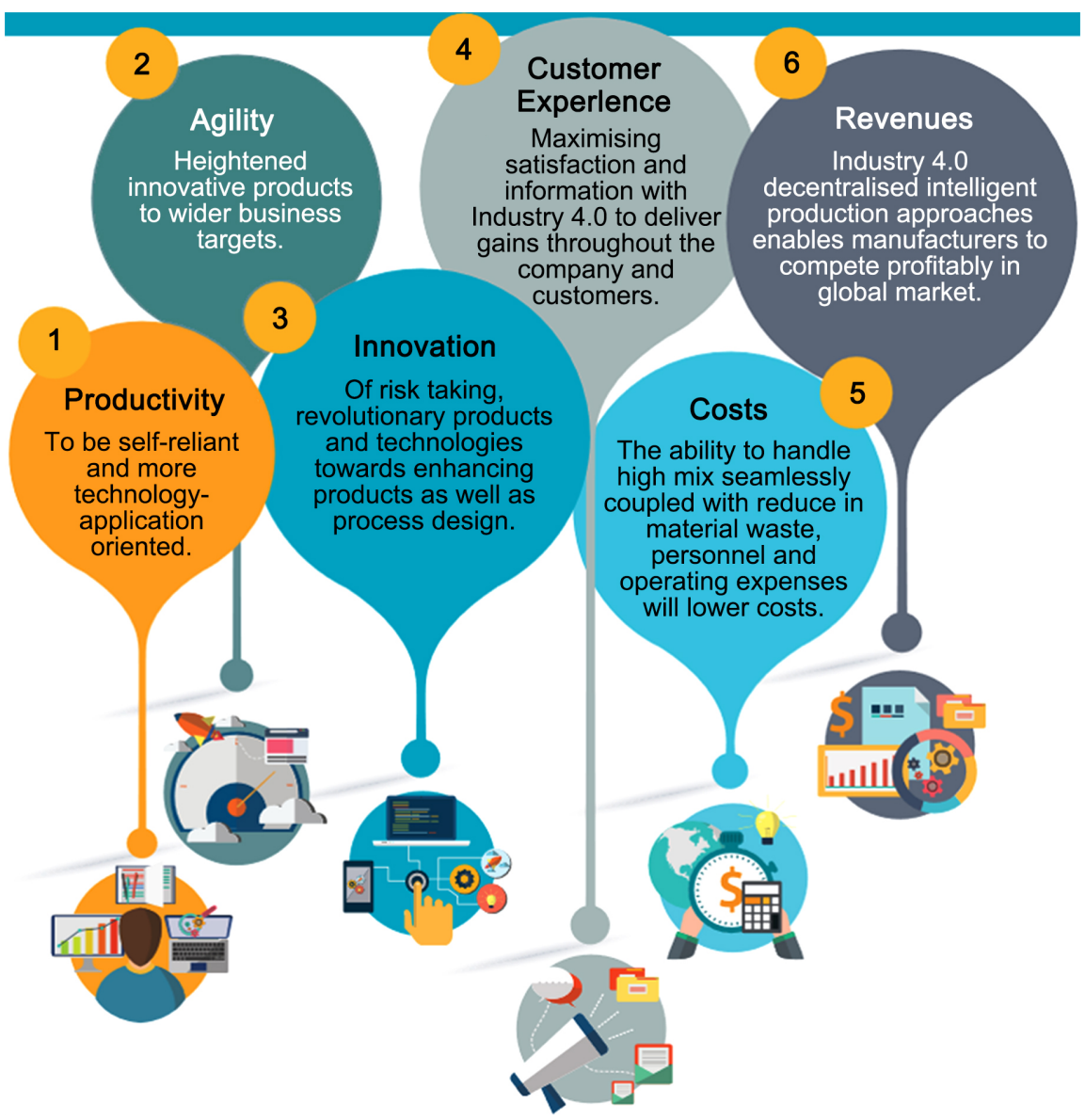

Figure 6. Industry 4.0 Advantages [12]. 
6) Revenue: With better quality, lower costs, higher quality-price ratio, and the ability to serve customers well, industry 4.0 puts manufacturers on a path to be a preferred supplier to current customers while also opening up to larger markets.

The emergence of industry 4.0 requires tackling different trends and challenges as follows:

\section{- Trend 1: Increasing product variety}

Deliver personalized products and services to customers with mass production efficiency (quality, costs, and time).

\section{- Trend 2: Shorter life cycles}

Shortening products, process and factory life cycles, as well as renewing production technologies and factory infrastructure

- Trend 3: Shorter lot sizes

- Trend 4: Non-stable demand

Dealing with non-stable non-cyclic demands and internal turbulence.

- Trend 5: Manufacturing tasks are becoming more complex

Deal with the engendered complexity of various activities of products, processes, and factory life cycles.

- Trend 6: Network modernization and intensification

Modernization and intensification of networks coupled with improved information flow and data availability.

- Trend 7: Responsibility and sensibilization

Become responsible and sensible in terms of social and environmental aspects in all our individual or collective efforts.

\section{Evolution of Value Chain and Supply Chain in Industry 4.0}

In this section, it is necessary to define two terms of value and effort before entering to the value chain and supply chain systems.

\subsection{Value and Effort}

Value as defined by the French National Institute of Statistics and Economic Studies (INSEE ${ }^{2}$ ), is equal to the value of production minus intermediate consumption.

Customer value is related to the use of a product or service, thereby removing it from personal values. The customers rather than the seller perceive this value. It is a trade-off between what the customer receives (e.g. quality, benefits, and worth) and what the customer gives up to acquire and use a product or service (e.g. price, sacrifices) [13].

Added value is defined as it reflects the extra value given by the enterprise through its activity (labor) to goods and services from third parties ${ }^{3}$. In other insight, added value can be seen in two different ways:

- Individual added value: This value is just devoted to the value which is given only to one product.

${ }^{2}$ https://www.insee.fr

${ }^{3}$ https://www.economie.gouv.fr 
- Collective added value: This added value is assessed by its impact on society and the environment, as well as its legacy of past practices.

Therefore, the added value reflects the transformation of value (or utility) induced by the activity of an enterprise through its work (or effort) to goods and services regardless of their origin. In this condition, the value transformation (or gradient) can be either positive or negative.

On the other hand, an effort, mental or physical, is a common feature of daily life, we encounter with effort every time, and we need to push ourselves into doing something [14].

According to this definition, the effort can be defined as a value-based decision as illustrated in Figure 7. This figure shows that by increasing the effort intensity, the cost of effort will increase. Although, the outcome (product) of effort will be less increased by this increase in effort intensity.

Besides, by increasing the effort intensity, the effort expected value will increase until the optimal value of effort, and will then diminished, making any ensuing effort unproductive. This diagram shows that there is a separation between the outcome of effort and its value in the real world. This diagram also shows that effort is costly and valued.

According to the study of Inzlicht et al. [14], it is evident that people will exert more effort for larger rewards. It is also predicted that adding effort reduces value for a given reward [14] [15] [16] Therefore, people prefer to pay a premium to outsource the effort to others [17]. By contrast, if these rewards require effort, people will sometimes value them more even for equivalent rewards.

\subsection{Human Effort vs. Technical Level of the Machine}

As illustrated in Figure 8, human effort is an individual effort involved to live and move around. It is shown that responsibility and sensibilization (social and environmental) of human beings, individually and collectively, are necessary for making an effort. As illustrated in this figure, humans first start to make an effort in terms of mobility by using animals like horses for his or her mobility. Over time, many different transportation means have been developed to replace human and animal power, i.e. buggies, first generations of automobiles, bikes,

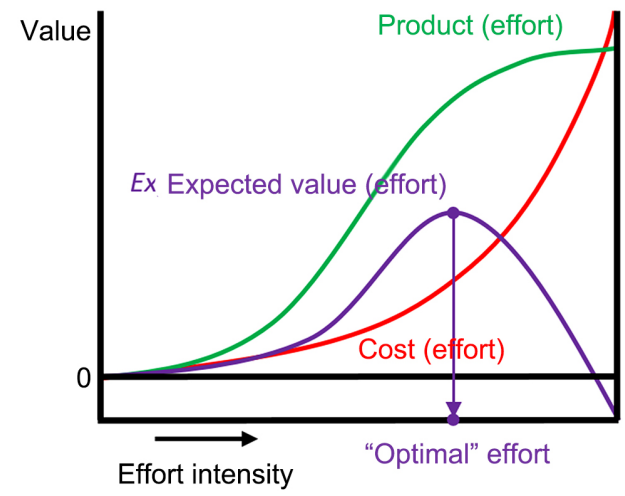

Figure 7. Effort as a value-based decision. 


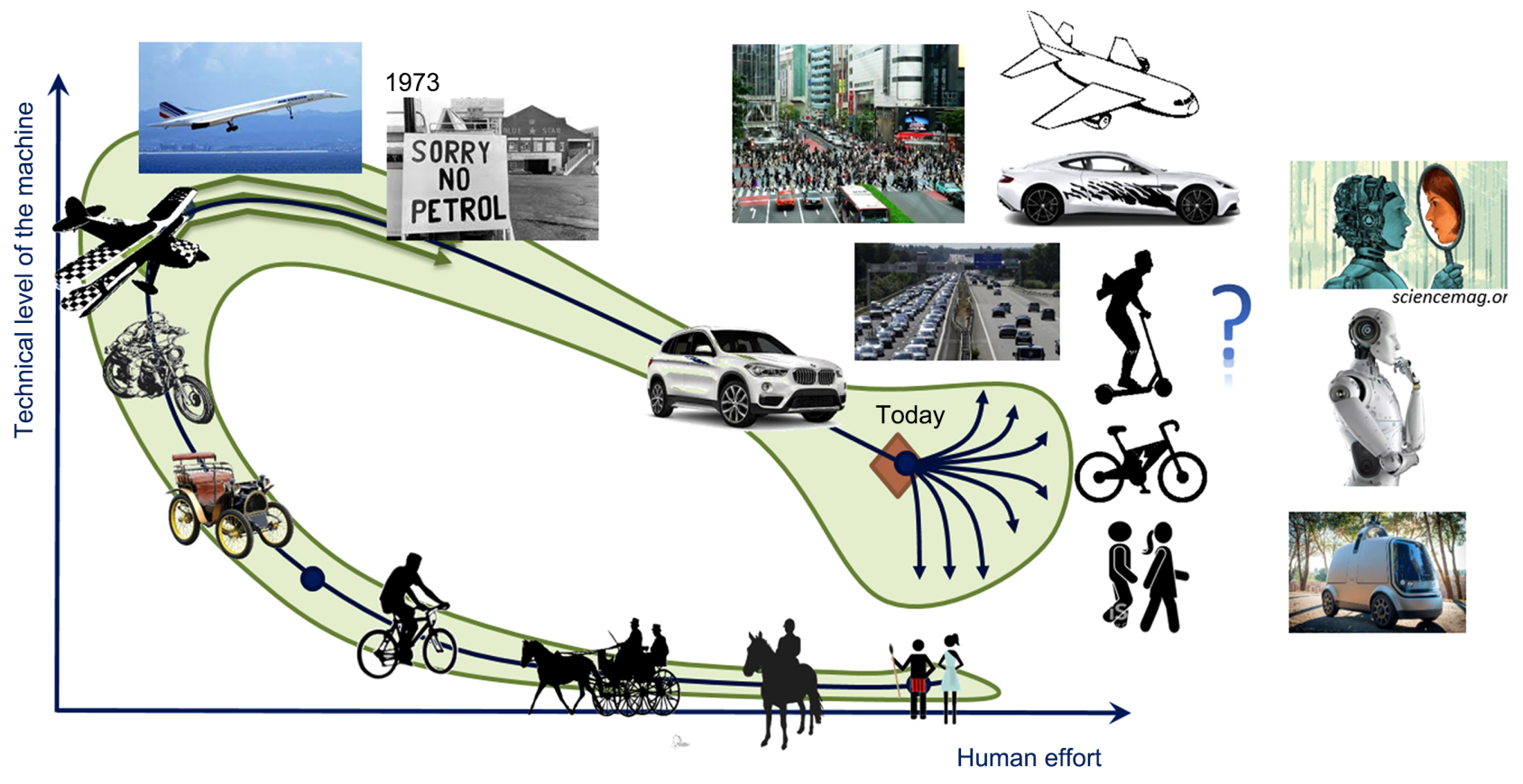

Figure 8. Human effort vs. Technical level of the machine.

motorcycles, airplanes, etc. However, nowadays there is a renewal in the use of transportation means, with a trend for individual and "low-tech" means, such as walking, ordinary bicycles or electrical ones, scooters. This trend can be explained by several factors: attention to healthcare issues, environmental concerns, but is also an answer to the growth of traffic jams in cities. Furthermore, the development of transportation systems day by day by improving technologies creates the opposite tendency to use high-tech automobiles and personalized cars. Moreover, with the arrival of an autonomous car, but also the entrance of robots in the everyday life, there is a fear for the future due to the increasing complexity of our close environment and the increasing distance between people's values and the machines they are using.

Empirical field studies have suggested that humans are superior to existing scheduling techniques and information systems regarding the human characteristics like flexibility, adaptability, learning, communication, negotiation, and intuition [18]. There is some component of human factors and decision-making in the production control of real factories. These factors can be responsible for the majority of sequencing and resource allocation decisions from the initial demand requirements until total production planning and scheduling [19]. Some human factors were analyzed in some works [20] [21] [22] [23]. The effect of human fatigue on performance in a Dual Resources Constrained (DRC) system was analyzed in the study of fruggiero et al. [20]. Workload balancing criteria is another significant factor that is investigated on scheduling problems like parallel machine [21] [22] [23]. Schwerdfeger et al. [23] presented a dynamic programming approach for solving the problem of minimizing the normalized sum of squared workload deviations on m identical machines. Moreover, anoth- 
er study [21] investigated this joint load balancing and parallel machines scheduling problem in order to make a decision to build the best schedule of $n$ jobs on $\mathrm{m}$ identical parallel machines in order to minimize the total tardiness and to find the equitable distribution of the machine?€?s time activity. Workload imbalance among the different machines is also minimized in the study of Ouazene et al. [22]. This problem is formulated as a linear mixed-integer program to minimize the difference between the greatest and smallest workload assigned to each machine.

\subsection{Value Chain}

The creation of value is managed through the value chain defined as the supply chain that creates the value [13]. A value chain is a set of activities adding value to raw materials through various processes and produce a valuable product or service in the market place [24] [25]. It is a series of integrated and dependent process that transforms the specifications into a finished deliverable. The value chain focused on the integration of activities while focusing on increasing value for the customer [13]. As illustrated in Figure 9, the value chain consists of several main activities including Inbound Logistics, Operations, Outbound Logistics, Marketing and Sales, Service, as well as support activities like organizational infrastructure, human resource management, research, development, and purchasing department [24]. One of the main issues in value chain management is the decision on price and worth. Price has been assigned to goods and services as a level to attract customers and to profit from sales, whereas worth illustrates the buyer's view of the price as it relates to the perceived benefits, or functions and attributes, of the product or service. When worth is equal or greater than price, the customer buys the product or service. Classic methods of setting prices based on cost, probability, and demand are consequently giving way of determining a price based on the customer's perceived value of the product's or service's attributes [13]. Today, smart pricing [27] is a decisive subject in the industrial world, which can help decision-makers to define the price based on demand. Therefore, the choice of selling price becomes a significant decision variable, influencing both consumer and producer.
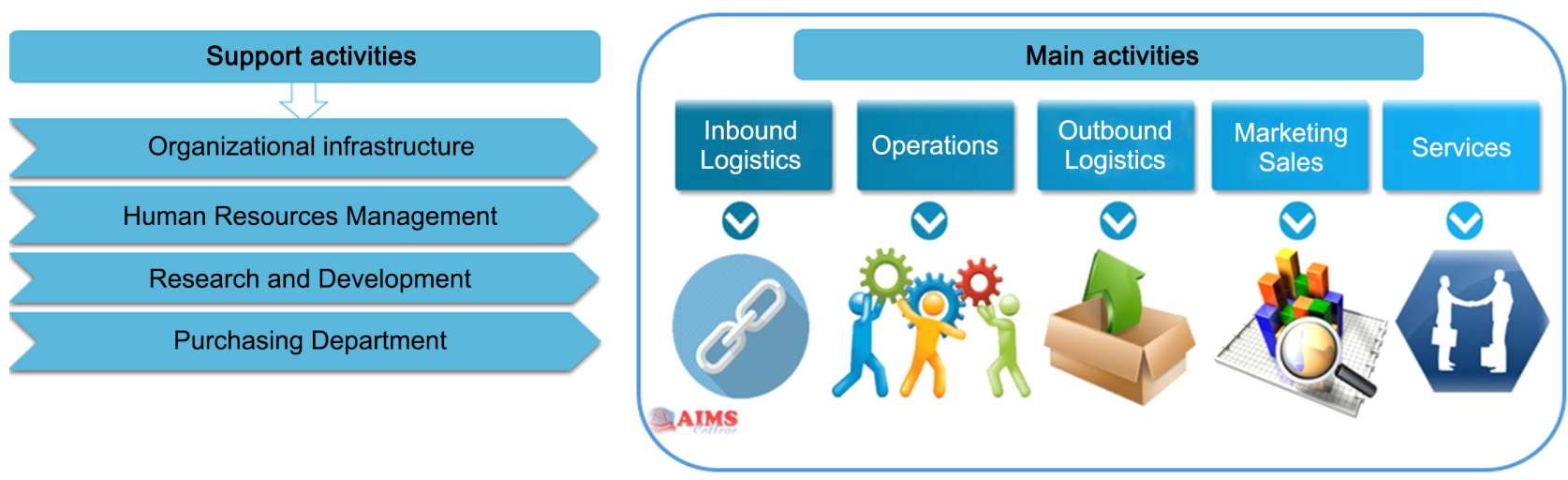

Figure 9. Value chain [24] [25] [26]. 


\subsection{Product-Process-Market (PPM)}

In 2002, Markham [28] addressed the Technology-Product-Market framework (TPM). TPM, as illustrated in Figure 10, is guiding managers in the process of discovering products based on a certain technology and consumer needs (markets). In this framework, there is a linear flow between parts. The products are differentiated by their technology and match customer needs, thus selling at a high rate. By identifying and analyzing the right market for a specific product, a further specification for the product attributes is expected to arise. In this current method, it is not possible to achieve some attributes and it is necessary to develop the technology in the path of unveiling those lacking characteristics.

Therefore, the design and configuration of the supply chain help the managers to integrate their product and process development process. A Product-ProcessSupply chain framework (Figure 11) is proposed. This framework enables companies to speed up their new product introduction process and to avoid future setbacks [29].

Companies focus on their core competencies related to product, market, and build up strategic partnerships with suppliers to whom they subcontract the manufacturing processes [30] [31]. Therefore, it is adequate to consider the Product-Market-Supply Chain framework to help the companies in their decisions during the scale-up phase (Figure 12) [32].

Today, these frameworks must be developed as a Product-Process-Market (PPM) framework. In this framework, product and market, as well as customers are the most important part of creating a supply chain system. The elements of this framework are interconnected and there is a shared flow between them. The product corresponds to the needs of each customer type. The production chain is adapted to the customer and the product. Nowadays, increasing a personalization trend or the necessity of some products like healthcare equipment in special

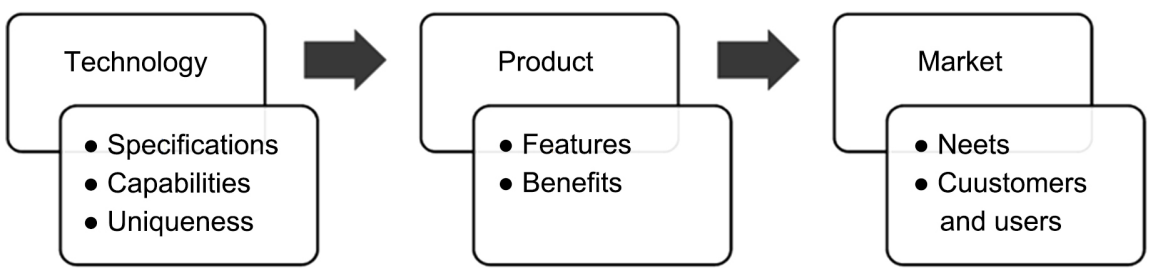

Figure 10. Technology product market [28].

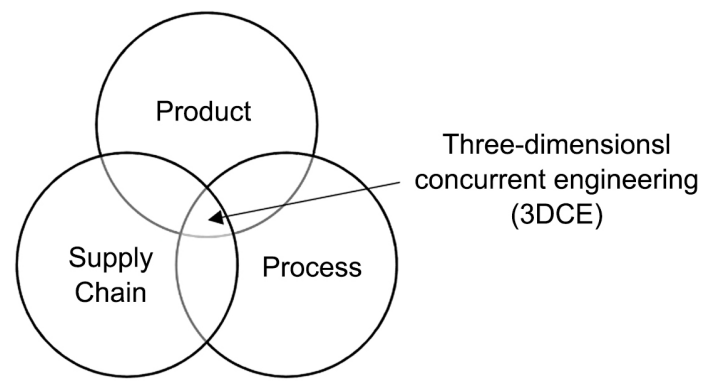

Figure 11. Product-Process-Supply chain (PPSC) framework [29]. 


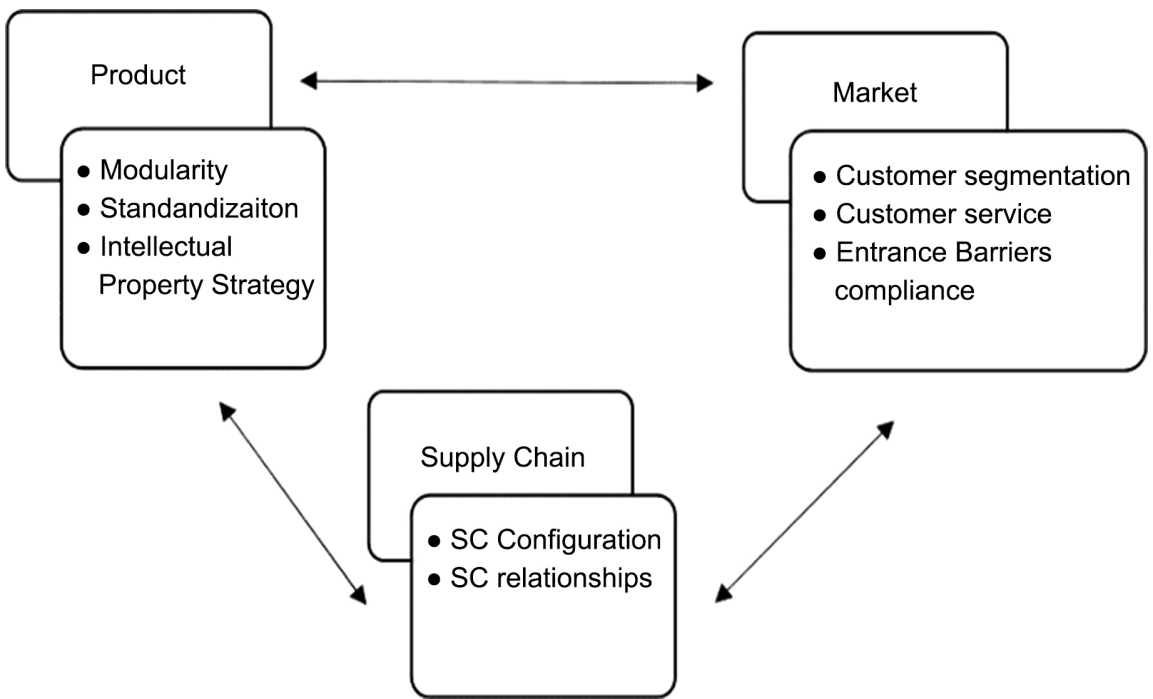

Figure 12. Product-Supply Chain-Market (PSCM) [32].

conditions like the COVID-19 crisis affects the total layers of supply systems as a network supply system (NSS) or a digital SC. Some researchers [33] [34] [35] [36] [37] also presented the impact of industry 4.0 on supply chain management. In the industry 4.0 era, this supply chain is defined as an interconnected supply chain network system or a digital supply chain (Supply chain 4.0) which will be discussed in the following.

\subsection{Network Supply System (NSS) and Supply Chain $\mathbf{4 . 0}$}

The supply chain consists of different partner channels including suppliers, manufacturers, distributors, and retailers that are in coordination and collaboration as shown in Figure 13. Supply Chain Management (SCM) encompasses the planning and management of all activities involved in sourcing and procurement, conversion, and all logistics management activities. It integrates supply and demand management within and across companies [38]. By developing different technologies over time, the classic supply chain [39] as a restricted logistics is transforming into the extended one. Moreover, the appearance of several performance indicators, which guarantee the remaining manufacturing sectors in this competitive market, creates a precondition to enter into a connected network supply system as a supply chain 4.0 in the age of industry 4.0 (see Figure 14). Furthermore, the presence of factors like core competence, globalization, improved transportation structures, and services, as well as growing information and communication technologies have gradually evolved the supply chains to form inter-organizational and interconnected layers as supply chain networks or a Network Supply System (NSS).

As illustrated in Figure 15, this network consists of the main layers as inbound logistics, production, outbound logistics, as well as sales and services. Within each layer, there is an intern supply chain to provide the necessary activities for this supply and production network. 


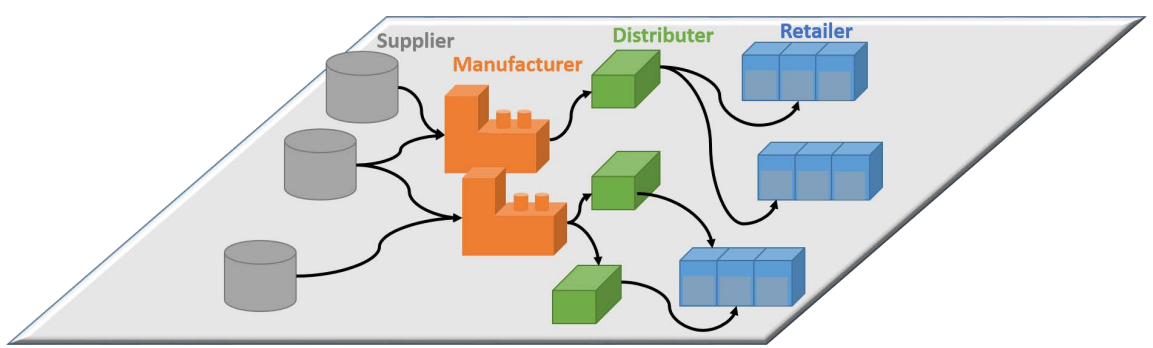

Figure 13. Classic supply chain.

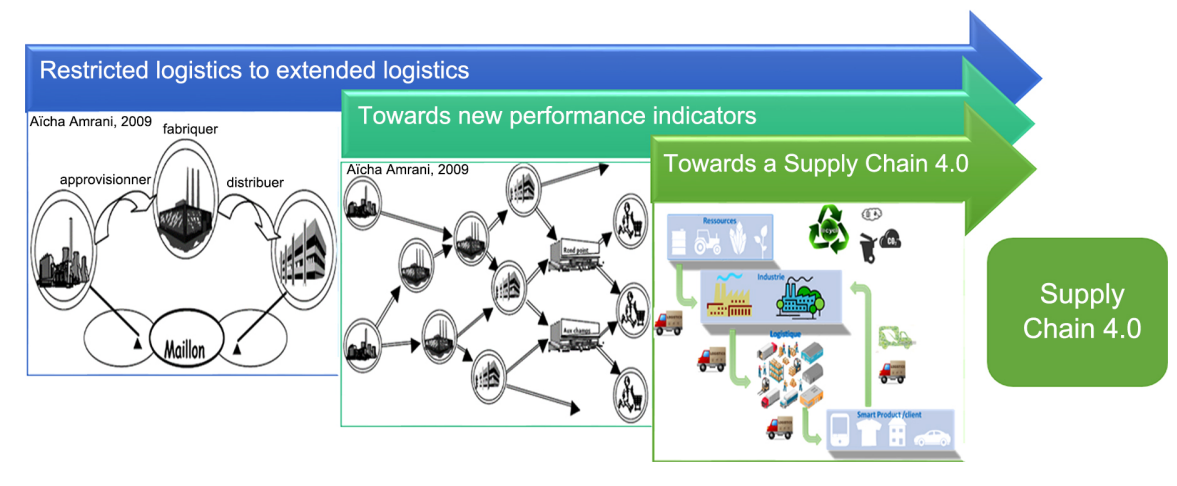

Figure 14. Toward supply chain 4.0.

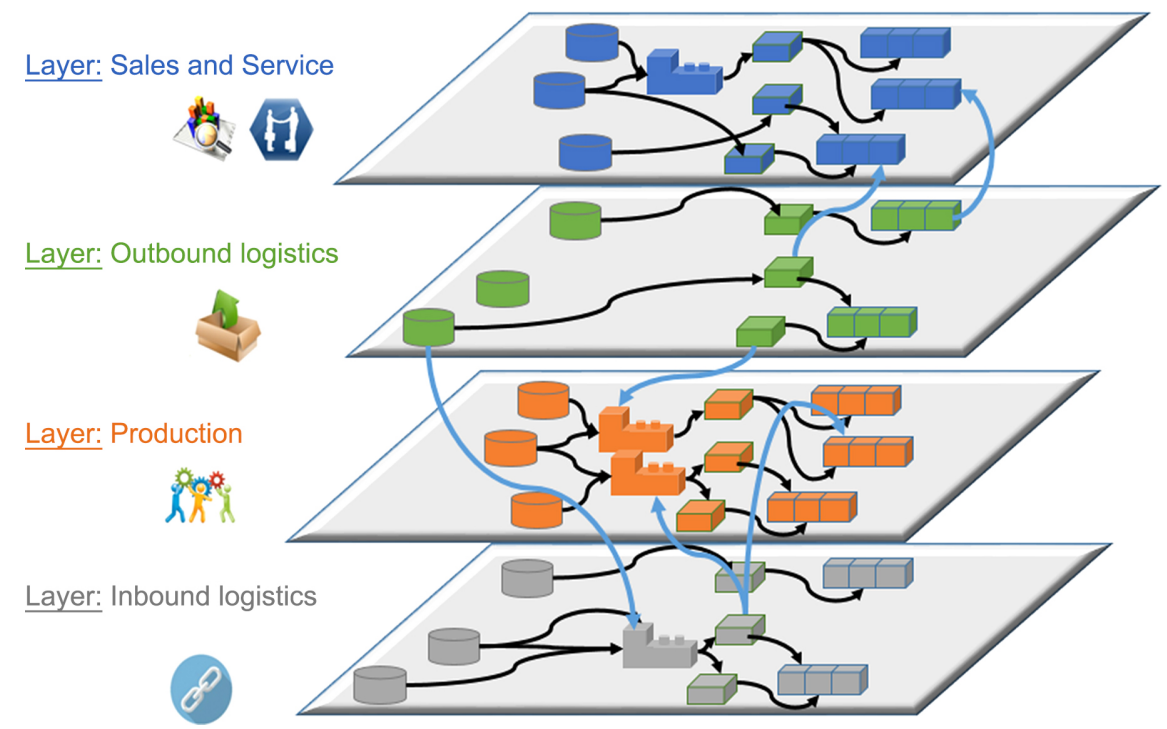

Figure 15. Network Supply System (NSS).

Supply chain 4.0 is an inter-connected network supply system. It is the utilization of the main pillars of industry 4.0 such as IoT, advanced robotics, and analytics of big data, etc. in supply chain management.

In supply chain 4.0, the technologies are in the service of supply chain components to improve performance and customer satisfaction. The companies must rethink about the design of their network supply systems. A digital supply chain enables companies to encounter new requirements of the customers, the new supplier challenges, as well as the remaining expectations in efficiency im- 
provement [40].

Moreover, different trends forcing the companies towards a digital supply system. These trends are the growth of the rural areas worldwide, wealth shifting into regions, the pressure to reduce carbon emissions, regulations of traffic for socioeconomic, reducing labor availability, as well as increasing ergonomic requirements, etc. Moreover, customer expectations have changed. Increasing online services, individualization, and customization, as well as eco-responsibility and environmental sensibility, are the factors that are important for customers. To respond to these trends and challenges, the supply chain system must become faster, more granular, more flexible, and more precise [40].

Figure 16 is an example of SC 4.0 presented by Mckinsey [40]. It shows that different technologies such as drone delivery, sensors, automatic machines, autonomous robots, etc. permit to provide a smart database, on-line shipment tracking, as well as smart pricing and online decision-making. In SC 4.0, the industries try to place sensors in everything, create networks everywhere, automate anything, and analyze everything to significantly improve performance and customer satisfaction. Nowadays, logistics has undergone a tremendous change from a purely operational function that reported to sales or manufacturing and

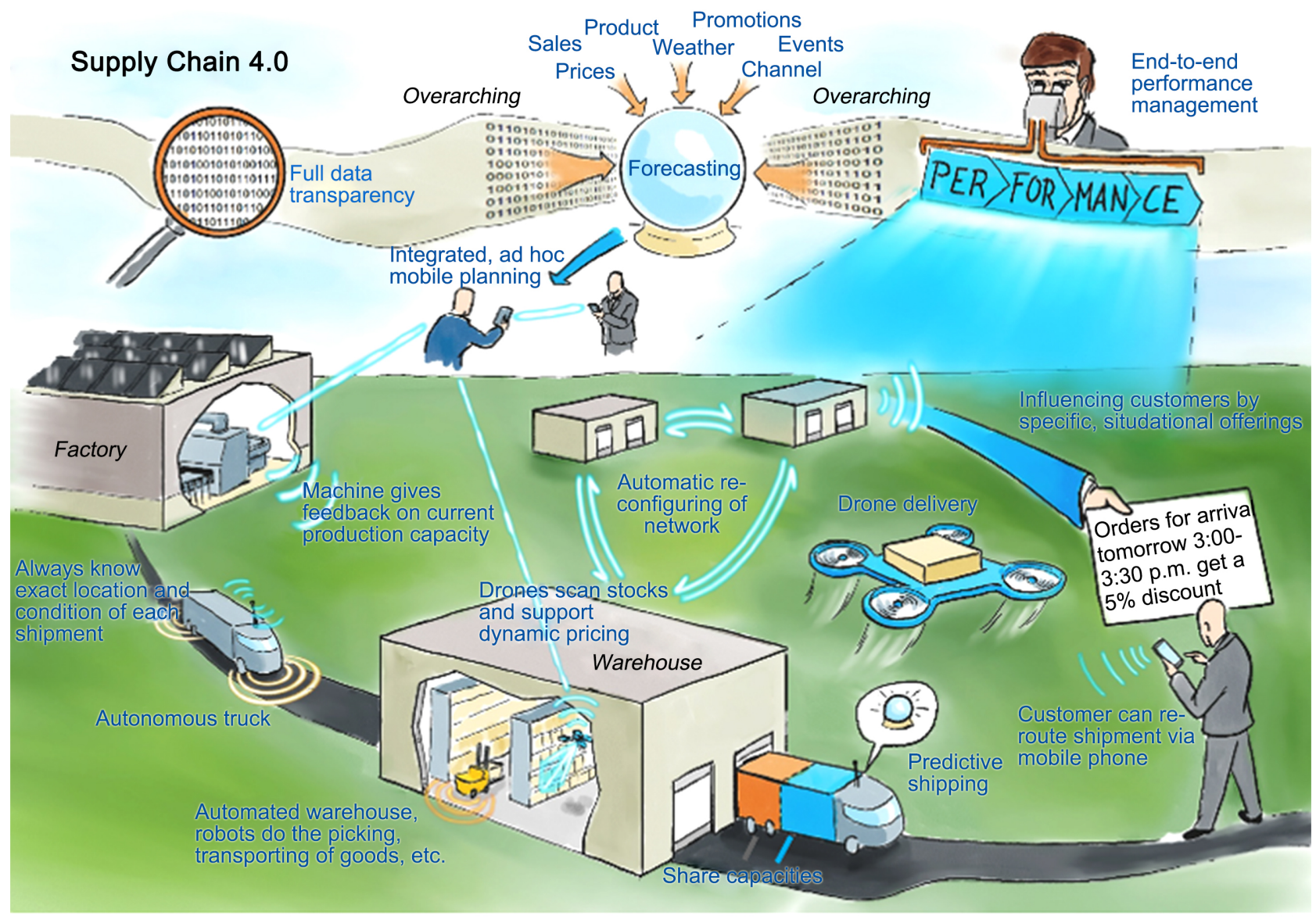

SOURCE: McKinsey

Figure 16. Supply chain 4.0 [40]. 
focused on ensuring the supply of production lines and the delivery to customers, to an independent supply chain management function. Moreover, the focus of supply chain management is on advance and connected planning processes, demand planning, smart pricing which ensures integrated operation into all step of supply chain system [40].

Therefore, industry 4.0 modifies the perception of value and added value. In addition, the restricted chain evolves into an extended chain of inter-modal nodes. There is an interaction between the supply chain layers. Linear relationships between chain parts become non-linear and complex. Today, the trends are toward an interconnected supply chain network or a digital supply chain. Moreover, these smart data analytics and digitalization modify decision-making strategies. The effects of this digital world on the decision-making approaches will be discussed in the next section.

\section{Digital Decision-Making}

Humans encounter different challenges in this digital transition and it modifies the traditional approaches of production philosophy. New strategies, requirements, and business models are emerging because of changing economic, environmental, and regulatory factors. It is necessary to identify and integrate the new performance indicators (KPIs) or metrics into decision-making processes. Smart data analytics creates an opportunity to make decisions faster and more precise.

Decision support systems have evolved over time. As illustrated in Figure 17, data is the main input of decision-making approaches. From 1950, data analysis is considered as operational support for decision-making, and respectively, decision-making aided by data analysis, decision-making driven by data analysis, and finally, automatic and real-time decision-making has emerged in this digital world. Different tools for decision-making are presented as customized analysis and spreadsheets, business intelligence, data mining, and machine learning. During the 21st century, other tools like big data, cyber-physics, and artificial intelligence (AI) have also emerged to tackle digitalization.

This intelligence and connectivity accelerate decision-making approaches. There is democratization to make the data and digital information accessible to anyone. Thanks to this connectivity, the hierarchies in the decision making are eliminated and the decision can be made at the process level. Artificial Intelligence creates the opportunity to analyze the data without a team analyst and the data can be used in prediction and reaction conditions. All these steps, shown in Figure 18, provide real-time decision-making approaches that make our planning faster, more precise, and more efficient [41].

This online decision-making can be used to solve several supply chain issues. It can be implemented in parallel and single machine scheduling problem, smart pricing, logistic problems, etc. The hierarchy of information could give priority to the acquisition of knowledge. This knowledge acquisition is expensive and it is essential to prioritize data by the use of a scoring function. 
Data analysis as an operational support
Decision-making

aided by data

analysis
Decision-making

driven by data

analysis
Automatic and real-time

decision making

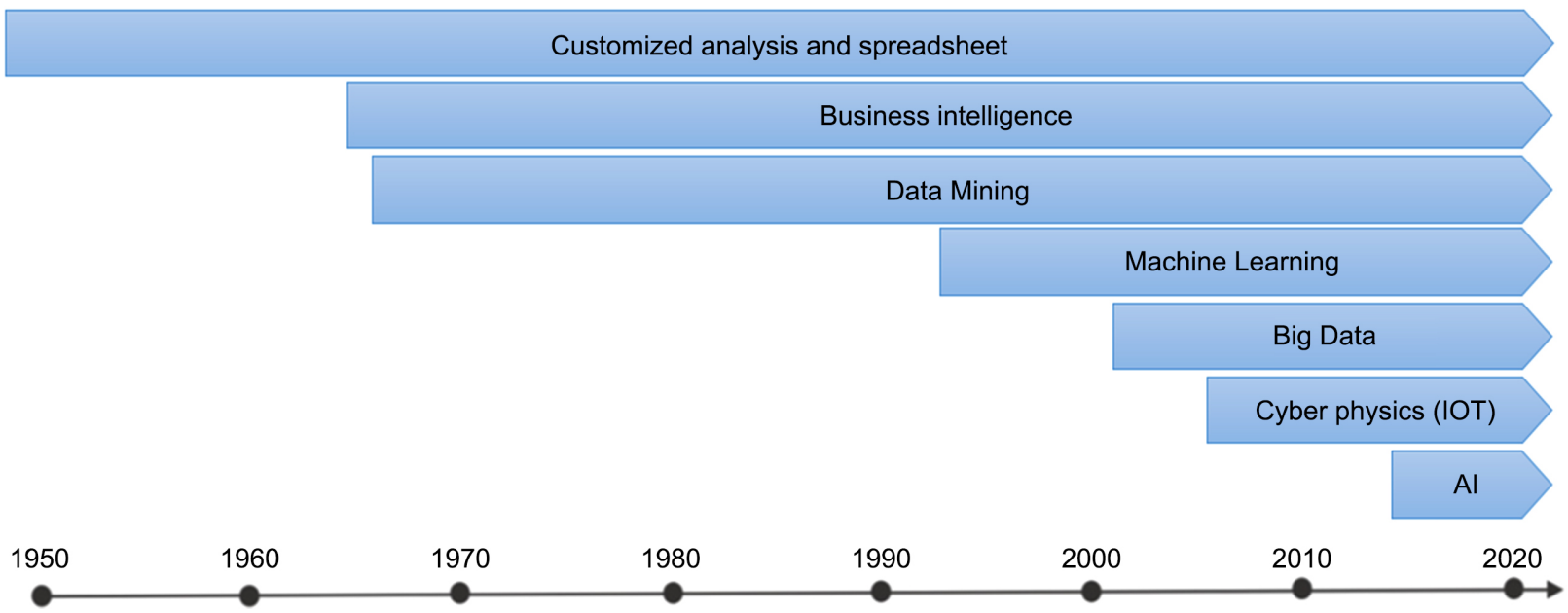

Figure 17. Decision support tools evolution.

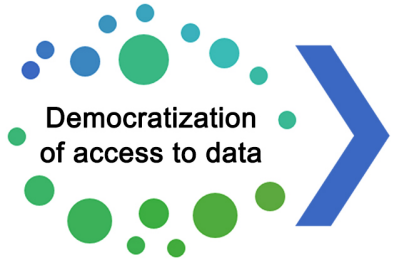

Making accessible the digital information
Elimination of hierarchies in the decision
Decisions made at the process level.

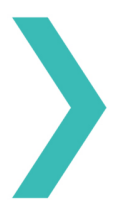

Al self-
analyzed data

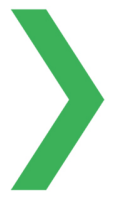

Predictive-

Reactive

Platform

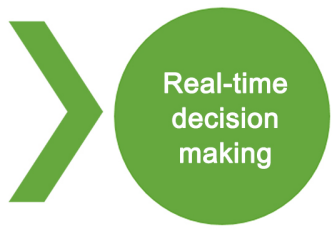
Collect and analyze data without a team of analysts
Dual-use data: prediction and reaction

Figure 18. Intelligent and connected decision-making approaches.

Therefore, there is a correlation between decision theory, patterns for decisions, and industrial developments. Moreover, digital transformation is changing the nature of information acquiring. It speeds up decision-making and changes its model. It is a trend towards decentralized and dynamic supply, generation, and decision nodes. Therefore, it is necessary to present and promote new practices for data analysis and information acquisition. This evolution affects the business world and demonstrates the necessity of new assessment tools for this new business world, which will be discussed in the next section.

\section{New Business World}

Nowadays, digitalization has moved from the strategy phase into the execution phase all around the world. This transformation is happening in different indus- 
tries and companies at a different speed. This digital transformation creates different levels of digital maturity and priorities in different sectors. In a survey conducted by Fujitsu Global [42], a questionnaire was prepared and answered by 1535 managers and decision-makers from large and medium-sized enterprises in key industrial sectors from 16 countries. The main objectives of this survey are to investigate where and how the new technologies are deployed, as well as identifying the challenges, business outcomes, and the capabilities for digital transformation. This survey demonstrated not only the current digital state but also, a guide for finding the significant factors to achieve the real digital transformation. Among these sectors, finance, manufacturing, and healthcare are primarily motivated to increase their operational efficiencies while transportation companies are more desired to respond to the competitive threats and retail companies tend to grow more. Figure 19 illustrates the current digital situation in different sectors including healthcare, transportation, retail, manufacturing, and finance. It compares the situation of different sectors that have planned, tested, and implemented digital transformation in each domain with the digital transformation projects that have already yielded positive results in each area.

As illustrated in Figure 19, about 30 of projects have delivered successful outcomes in finance and retail, while in other sectors these percentages are: transportation (25\%), manufacturing (21\%), and healthcare (14\%). Moreover, it is shown that on-line companies (97\%) are the vanguard in this digital transformation rather than non-online companies $(67 \%)$.

Besides, this study presented six factors for determining the success of outcomes from digital transformation projects including leadership, people, agility, business integration, ecosystem, and value derived from data. This research demonstrates that AI (Artificial Intelligence) plays a vital role in digitalization and 68 of business leaders believe that in the future, people and AI will work collaboratively [42].

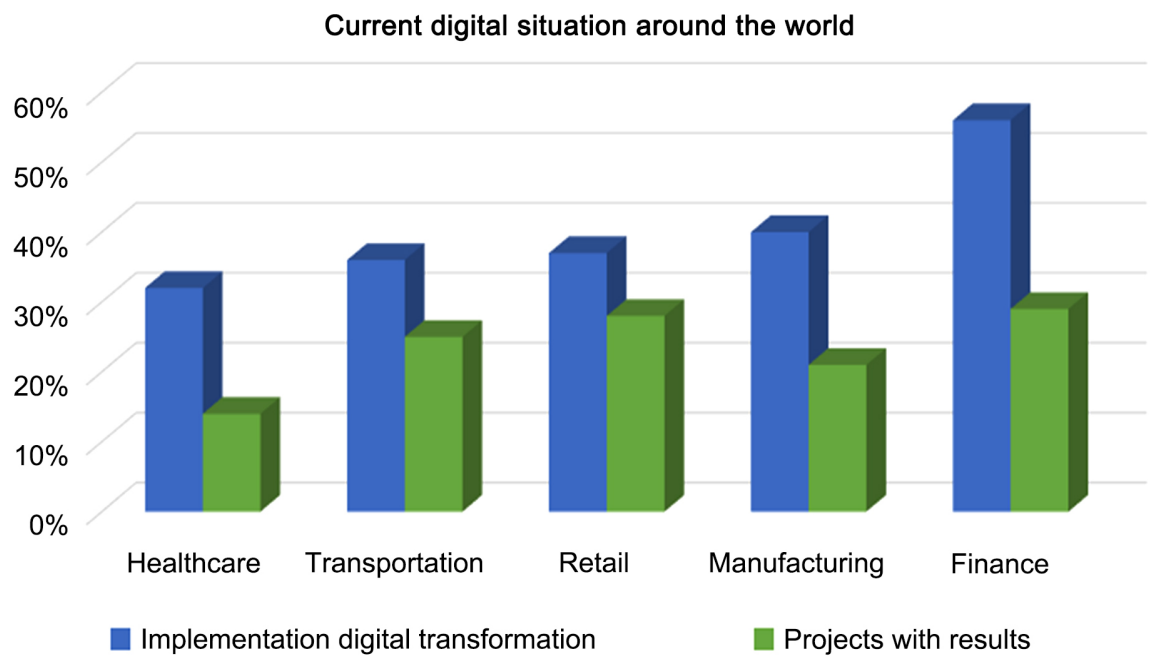

Figure 19. Current digital situation around the world-Inspired from the study of Fujitsu Global [42]. 


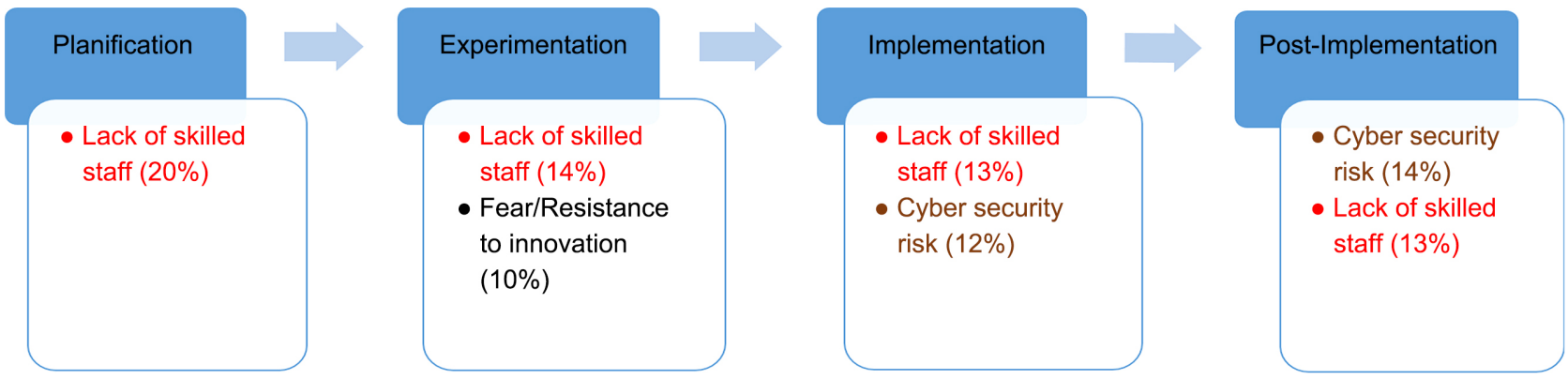

Figure 20. The main challenges of the digital transformation.

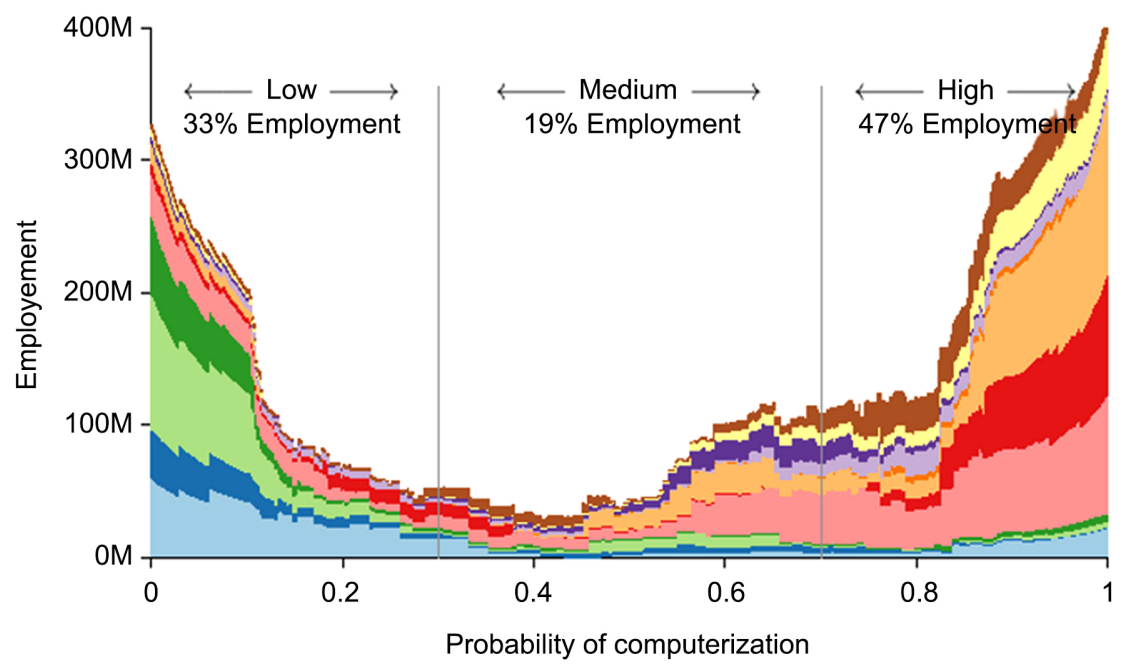

- Transportation and Material moving

- Production

- Installation, Maintenance and Repair

- Construction and Extraction

- Farming, Fishing and Forestry

- Office and Administrative support

- Sales and Related

- Service

- Healthcare Practitionners and Technical

- Education, Legal, Community service, Arts and Média

- Computer, Engineering and Science

- Management, Business and Financial

Figure 21. Employment affected by computerization [43]. 
must overcome the engineering bottlenecks to achieve digitalization and automation in the next decades. According to this figure, most workers in transportation and logistics occupations, administrative and support workers, and laborers in production occupations are in the front line of substitution's risk by computer capital. For instance, the computerized car, equipped by sensors and automatizing in transportation, uses big data to access to information in administrative and office support domains, as well as autonomous robots on production sites are the technologies that help computerization in these sectors. Moreover, services, sales, and construction occupations also exhibit high probabilities of transformation. Personal and household service robots, a high degree of social intelligence, and on-line markets lead these sectors in this digital transformation.

To summarize, recent developments in machine learning put a substantial share of employment at risk in the near future. However, this wave of automation will be followed by a subsequent slowdown in computerization for labor substitution, due to persisting inhibiting engineering bottlenecks to computerization, as well as the lack of skilled staff, fear from changes and innovation in a society and security risk as discussed before.

To tackle this digital transformation, it is necessary to identify the crucial competencies in this era. World Economic Forum performed an analysis of necessary competencies in 2015 and 2020. As illustrated in Figure 22, complex problem solving, critical thinking, creativity, people management, coordination with others, judgment and decision-making, service orientation, and negotiation are the competencies that are remained in top skills but with some modifications in ranking from 2015 to 2020 . For example, creativity among these skills is coming from the tenth rank to the third one due to the entrance of new products, new technologies, and new ways of working. Besides, emotional intelligence and cognitive flexibility are entered as top skills in 2020. Moreover, quality control and active listening lost their positions due to digitalization [44].

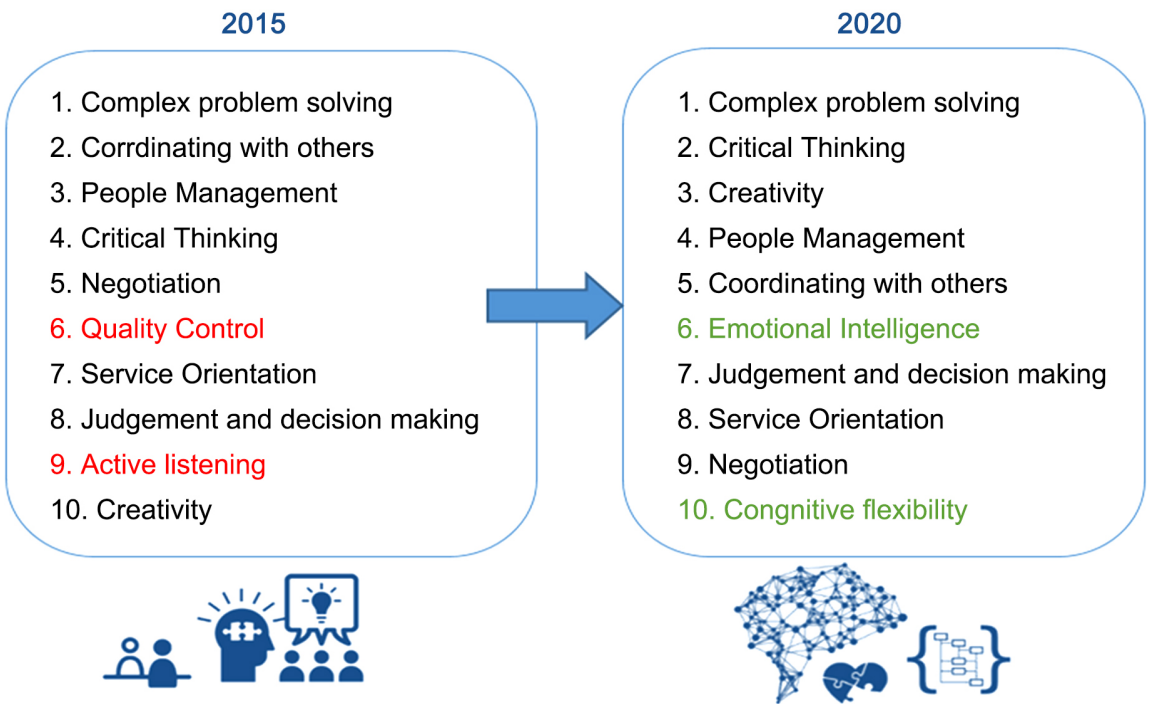

Figure 22. The necessary competences in 2015 and 2020 [44]. 
Moreover, these companies must evaluate their digitalization level to remain in this competitive world. Therefore, it is necessary to assess them according to the industry 4.0 criteria and features. Some business models were presented [45] [46] [47] [48] to determine the maturity readiness of companies. These models aim to assess the actual situation of companies in terms of process and organization digital readiness. These analyzes create a guide for the industrial sector in terms of industry 4.0 concepts and features.

\section{Discussion}

Today, digital transformation is a worldwide concern. This digitalization in industrial and social infrastructures is accelerating through the world. An increasing number of countries have developed plans to tackle this digital transformation. These countries can be classified into three distinct categories. The first one considers the pioneering and leading countries. Japan started this evolution in 1988 by its plan as "New Manufacturing Technology" and "The intelligent Manufacturing System Project" continued it in 1991. Between 2011 and 2013, Japan presented its plan as "Science and Technology", and in 2016, they presented Japanese Society 5.0. Germany as a leader of "Industry 4.0" began to enter this era in 2004. As outsiders, South Korea followed the "Manufacturing Innovation 3.0" Plan from 2013 to 2017. Also, South Korean industries planned to reach 10,000 smart factories in 2020 to have highly robotized industries and smart factories with high-quality production. Moreover, China focused on the plan "Made in China 2025" to increase the Chinese content of major components and materials to 40 in 2020 and 70 in 2025. They also anticipate becoming the leader of the world industry in 2049. The last category represents countries that started their plans recently but are less ambitious than the two other categories. It consists of the USA and the UK. They developed different programs, "Promoting research on future technologies" and "Advanced Manufacturing Partnership" announced by the U.S. government in 2014. In 2010, the UK presented a plan as "Rapid transition from advanced research to the market". Moreover, the "Catapult Network/Digital Catapult” program was presented by the British government innovation agency for the digital and software industry in 2011.

Therefore, the wave of digital transformation is the common element that is driving such activities, and thus digital transformation becomes a pillar of industrial policy. Besides, nowadays the world is encountered with global scale challenges, including depletion of natural resources, global warming, growing economic inequality, terrorism, and healthcare crisis with growing system complexity and uncertainty at all levels [49].

As mentioned before, Japan as the leader of digitalization presented Society 5.0 concept in 2016. As illustrated in Figure 23, human history defines different stages of societies. Society 1.0 is presented as groups of people hunting and gathering in harmonious coexistence with nature. Agricultural cultivation, increased organization, and nation-building created Society 2.0. Industrialization 


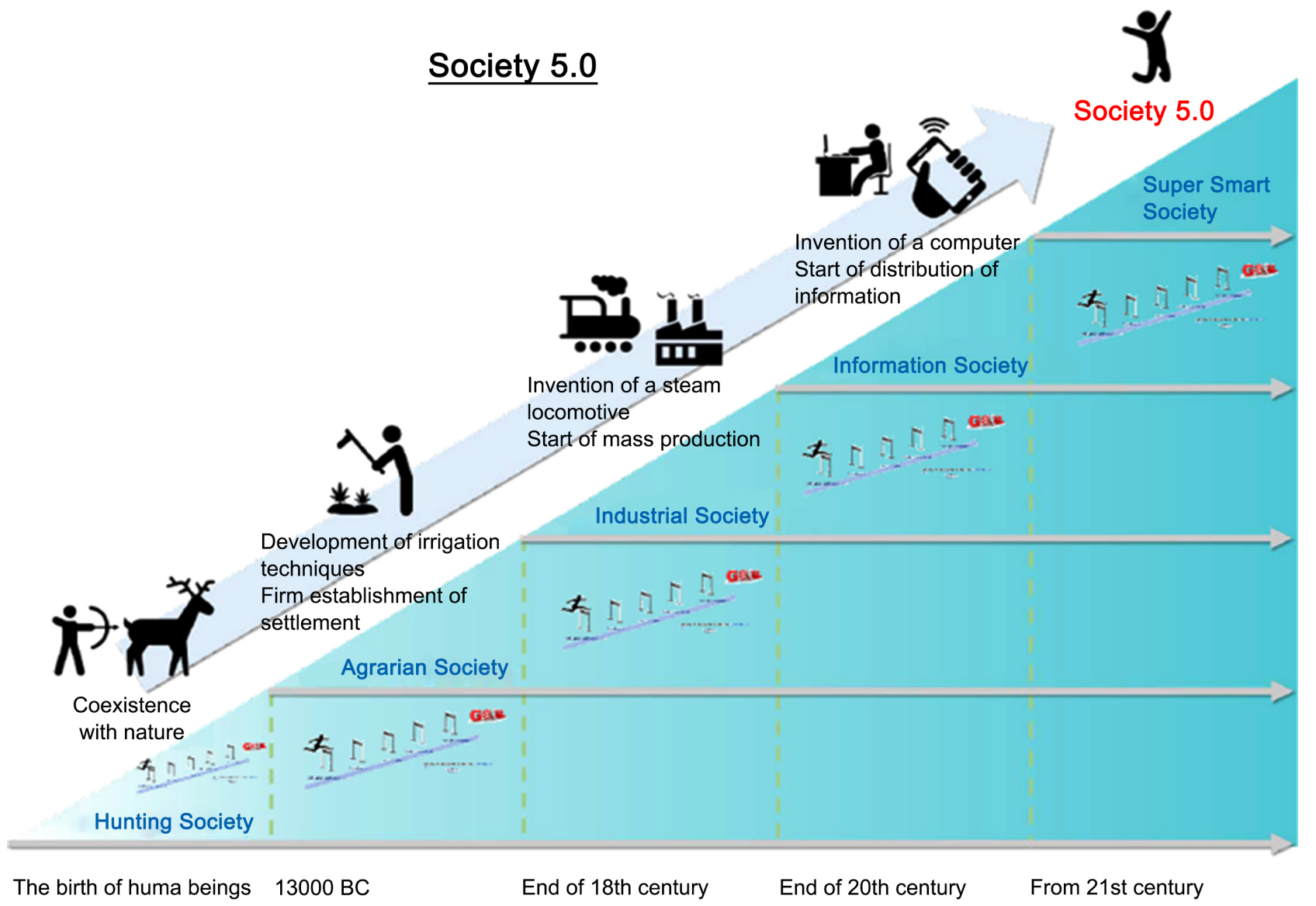

Figure 23. Towards Society 5.0 [50]. 
forming a knowledge foundation. The fourth one is human resources that always have a fear of changing. It is necessary to define a dynamic agreement of all citizens in the new economy and society. Finally, the last obstacle is social acceptance, which requires an integration of advanced technology and society [50].

\section{Conclusions and Suggestions}

This paper aims to discuss industry 4.0 and its effect on the industrial world and global society. This study is devoted to a comprehensive overview of industrial revolutions, manufacturing production plans over time, as well as a detailed analysis of industry 4.0 and its features. The impact of industry 4.0 in the industrial world including the evolution of supply chain systems and value chain, effort and value, as well as digital decision making and business models are investigated.

In this study, it is shown that over time and by the development of technologies, three revolutions have appeared in the industrial world and the term "Industry 4.0 " is devoted to the fourth revolution but this " 4 th revolution" is coming without sufficient temporal hindsight to proclaim it. It can be concluded that this revolution is only an evolution that is coming through the development of several technologies and the need to adaption for several industries in order to remain in this competitive industrial world.

Human natural tendency to live in welfare, the importance of healthcare, as well as the environmental and social aspects, create a conflict in the relation between machine and human. It is a probability to reach saturation in terms of technology and people return to the first level of technicity for considering the social and environmental aspects of our individual and collective life. Besides, this evolution creates several advantages in industries, as it is faster and more precise. It affects all industrial sectors and all the supply chain systems are tented

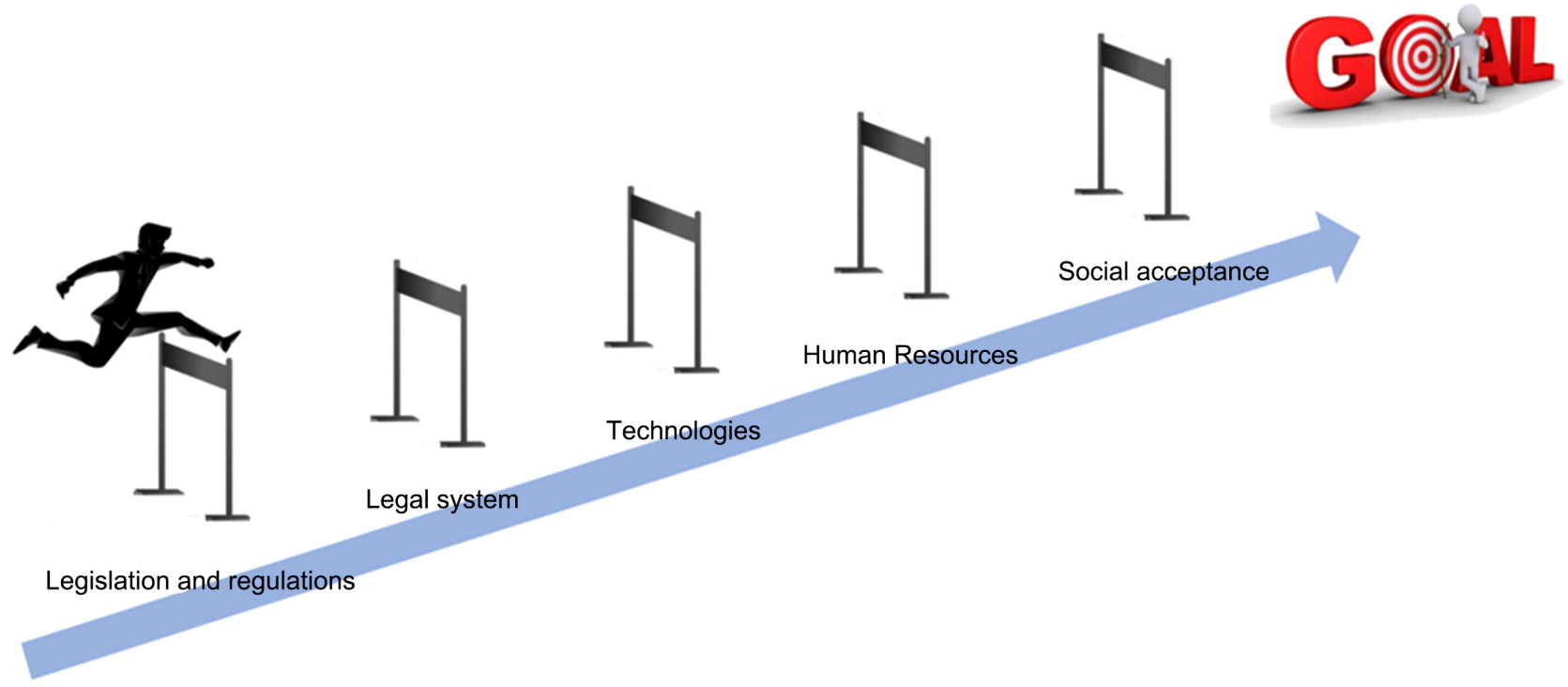

Figure 24. The five walls and obstacles to achieve a goal-inspired by Kidanren as Japan Business federation [50]. 
to become more interconnected, faster, and precise. Different pillars of industry 4.0 create productivity, agility, innovation, satisfaction for customers, as well as cost-effective operation and increasing the profit for each sector.

Decision-making approaches are also affected by this evolution and smart data help decision maker to have a plan more precise, faster, and more efficient.

This evolution affects different business sectors in terms of communication, consumption, and work. Therefore, they have no choice but to adapt to these changes. All the sectors are led towards decentralized and dynamic supply, generation, and decision nodes. Moreover, the crisis like COVID-19 with that we are encountering in 2020, necessitates defining an interconnected supply chain system. Also, the intelligent decision making approaches based on the different situations and real data-base by considering different indicators like resilience, economic, and ecologic factors can be helpful to manage the situation.

The digital transformation leads to a change of 50 of the professions in the near future. Some professions are at risk of disappearing. Therefore, basic changes and new skills are also necessary to adapt to these new professions. For this purpose, industrial sectors need to analyze their level of digital maturity in order to remain in this competitive world. Nowadays, there is no general assessment tool that considers all industrial sectors and all main pillars of industry 4.0 that can be provided in future research. Therefore, there is a perilous need to adapt with this transformation including incubated and shared innovations, preservation, and transfer of human knowledge, business model adapted to imminent changes in the market and society, as well as finding a multi-scale solution (local, national, and international) to remain in this industrial world. Therefore, it is necessary to provide a general and robust assessment model for evaluating digital maturity, as well as providing a general road map that helps the companies in their digital transformation in different aspects like people and culture, base technologies, value chain, etc.

\section{Acknowledgements}

The authors gratefully acknowledge the Industrial Chair Connected-Innovation and its industrial partners (https://chaire-connected-innovation.fr), as well as FEDER (Le Fonds Européen de Développement Régional) for their financial supports.

\section{Conflicts of Interest}

The authors declare no conflicts of interest regarding the publication of this paper.

\section{References}

[1] Gökalp, E., Sener, U. and Eren, P.E. (2017) Development of an Assessment Model for Industry 4.0: Industry 4.0-mm. In: Mas, A., Mesquida, A., O’Connor, R., Rout T. and Dorling A., Eds., Software Process Improvement and Capability Determination. SPICE 2017. Communications in Computer and Information Science, Springer, Cham, vol. 770, 128-142. https://doi.org/10.1007/978-3-319-67383-7 10 
[2] Bartodziej, C.J. (2017) The Concept Industry 4.0. In: The Concept Industry 4.0, Springer, Wiesbaden, 27-50. https://doi.org/10.1007/978-3-658-16502-4 3

[3] Horváth, B. (2018) The Recognition of Resource Use through Industrial Development from a Social Perspective. Studia Mundi-Economica, 5, 68-78.

https://doi.org/10.18531/Studia.Mundi.2018.05.01.68-78

[4] Koren, Y. (2010) The Global Manufacturing Revolution: Product-Process Business Integration and Reconfigurable Systems. John Wiley \& Sons, Hoboken, New Jersey, vol. 80. https://doi.org/10.1002/9780470618813

[5] Michael Geisinger (2015) Game-Based Synthesis for Distributed Control of Industrial Assembly Lines. PhD Thesis, Technische Universität München, München.

[6] Mehrabi, M.G., Ulsoy, A.G. and Koren, Y. (2000) Reconfigurable Manufacturing Systems: Key to Future Manufacturing. Journal of Intelligent Manufacturing, 11, 403-419. https://doi.org/10.1023/A:1008930403506

[7] Interbrand (2019) Best Global Brands Rankings. https://www.interbrand.com/best-brands/

[8] Oztemel, E. and Gursev, S. (2020) Literature Review of Industry 4.0 and Related Technologies. Journal of Intelligent Manufacturing, 31, 127-182. https://doi.org/10.1007/s10845-018-1433-8

[9] Deloitte, A.G. (2015) Industry 4.0 Challenges and Solutions for the Digital Transformation and Use of Exponential Technologies. McKinsey Global Institute.

[10] Rüßmann, M., Lorenz, M., Gerbert, P., Waldner, M., Justus, J., Engel, P. and Harnisch, M. (2015) Industry 4.0: The Future of Productivity and Growth in Manufacturing Industries. Boston Consulting Group, 9, 54-89.

[11] Asadollahi-Yazdi, E., Gardan, J. and Lafon, P. (2019) Multiobjective Optimization Approach in Design for Additive Manufacturing for Fused Deposition Modeling. Rapid Prototyping Journal, 25, 875-887. https://doi.org/10.1108/RPI-07-2018-0186

[12] Produktiviti, L. and Sultan, J. (n.d.) The Race towards Industry 4.0. http://www.mpc.gov.my/wp-content/uploads $/ 2018 / 11 /$ The-Race-Towards-Industr y-4.0.pdf

[13] Al-Mudimigh, A.S., Zairi, M., and Ahmed, A.M.M. (2004) Extending the Concept of Supply Chain: The Effective Management of Value Chains. International Journal of Production Economics, 87, 309-320. https://doi.org/10.1016/j.ijpe.2003.08.004

[14] Inzlicht, M., Shenhav, A., and Olivola, C.Y. (2018) The Effort Paradox: Effort Is Both Costly and Valued. Trends in Cognitive Sciences, 22, 337-349. https://doi.org/10.1016/j.tics.2018.01.007

[15] Kool, W., McGuire, J.T., Rosen, Z.B. and Botvinick, M.M. (2010) Decision Making and the Avoidance of Cognitive Demand. Journal of Experimental Psychology: General, 139, 665-682. https://doi.org/10.1037/a0020198

[16] Hull, C.L. (1943) Principles of Behavior. Appleton-Century Crofts, New York, vol. 422.

[17] Johnson, A.W. and Gallagher, M. (2011) Greater Effort Boosts the Affective Taste Properties of Food. Proceedings of the Royal Society B: Biological Sciences, 278, 1450-1456. https://doi.org/10.1098/rspb.2010.1581

[18] Mackay, K.N., Buzacott, J.A. and Safayeni, F.R. (1989) Knowledge Based Production Management Systems.

[19] McKay, K.N. and Wiers, V.C.S. (2006) The Human Factor in Planning and Scheduling. In: Herrmann J.W., Ed., Handbook of Production Scheduling. International Series in Operations Research \& Management Science, Springer, Boston, MA, vol 89, 23-57. https://doi.org/10.1007/0-387-33117-4_2 
[20] Fruggiero, F., Riemma, S., Ouazene, Y., Macchiaroli, R. and Guglielmi, V. (2016) Incorporating the Human Factor within Manufacturing Dynamics. IFAC-Papers OnLine, 49, 1691-1696. https://doi.org/10.1016/j.ifacol.2016.07.825

[21] Ouazene, Y., Hnaien, F., Yalaoui, F. and Amodeo, L. (2011) The Joint Load Balancing and Parallel Machine Scheduling Problem. In: Hu, B., Morasch, K., Pickl, S. and Siegle, M. Eds., Operations Research Proceedings 2010. Operations Research Proceedings (GOR (Gesellschaft für Operations Research e.V.)), Springer, Berlin, Heidelberg, 497-502. https://doi.org/10.1007/978-3-642-20009-0 79

[22] Ouazene, Y., Yalaoui, F., Chehade, H. and Yalaoui, A. (2014) Workload Balancing in Identical Parallel Machine Scheduling Using a Mathematical Programming Method. International Journal of Computational Intelligence Systems, 7, 58-67. https://doi.org/10.1080/18756891.2013.853932

[23] Schwerdfeger, S. and Walter, R. (2018) Improved Algorithms to Minimize Workload Balancing Criteria on Identical Parallel Machines. Computers \& Operations Research, 93, 123-134. https://doi.org/10.1016/j.cor.2018.01.018

[24] Kramer, M.R. and Porter, M. (2011) Creating Shared Value. FSG.

[25] Porter, M.E. (1985) The Competitive Advantage: Creating and Sustaining Superior Performance. Free Press, New York, 167-206.

[26] Arif (n.d.) Value Chain Definition-What Is Value Chain? https://aims.education/study-online/what-is-value-chain-definition/

[27] Couzon, P., Ouazene, Y. and Yalaoui, F. (2020) Joint Optimization of Dynamic Pricing and Lot-Sizing Decisions with Nonlinear Demands: Theoretical and Computational Analysis. Computers \& Operations Research, 115, 104862. https://doi.org/10.1016/j.cor.2019.104862

[28] Markham, S.K. (2002) Moving Technologies from Lab to Market. Research-Technology Management, 45, 31-42. https://doi.org/10.1080/08956308.2002.11671531

[29] Fine, C. (2006) Value Chain Design and Three-Dimensional Concurrent Engineering. Kim, K., "Business Eco-Systems: Relationships between Large and Small Firms", Federation of Korean Industries.

[30] Claro, J. and Barros, A.C. (2012) Supply Chain Strategy in High-Tech Start-Ups.

[31] Tedim, A.R., Barros, A.C., Maia, C. and Godsell, J. (2015) Start-Ups of Wearable Technologies: Challenges in Supply Chain Strategic Decisions. 22nd International Annual EurOMA Conference, Trondheim, Norway, 17 June-July 222015.

[32] Valente, L.F., Barros, A.C., Maia, C. and Cunha, J.P. (2018) Start-Ups: Integrating Product, Market and Supply Chain Decisions to Build-Up Market Entry Capabilities.

[33] Foerstl, K., Azadegan, A., Leppelt, T. and Hartmann, E. (2015) Drivers of Supplier Sustainability: Moving beyond Compliance to Commitment. Journal of Supply Chain Management, 51, 67-92. https://doi.org/10.1111/jscm.12067

[34] Lim, M.K., Tseng, M.-L., Tan, K.H. and Bui, T.D. (2017) Knowledge Management in Sustainable Supply Chain Management: Improving Performance through an Interpretive Structural Modelling Approach. Journal of Cleaner Production, 162, 806-816. https://doi.org/10.1016/j.jclepro.2017.06.056

[35] Madani, S.R. and Rasti-Barzoki, M. (2017) Sustainable Supply Chain Management with Pricing, Greening and Governmental Tariffs Determining Strategies: A GameTheoretic Approach. Computers \& Industrial Engineering, 105, 287-298. https://doi.org/10.1016/j.cie.2017.01.017

[36] Pagell, M. and Shevchenko, A. (2014) Why Research in Sustainable Supply Chain Management Should Have No Future. Journal of Supply Chain Management, 50, 44-55. https://doi.org/10.1111/jscm.12037 
[37] Riel, A. and Flatscher, M. (2017) A Design Process Approach to Strategic Production Planning for Industry 4.0. In: Stolfa, J., Stolfa, S., O’Connor, R. and Messnarz, R., Eds., Systems, Software and Services Process Improvement. EuroSPI 2017. Communications in Computer and Information Science, Springer, Cham, vol. 748, 323-333. https://doi.org/10.1007/978-3-319-64218-5 27

[38] Gibson, B.J., Mentzer, J.T. and Cook, R.L. (2005) Supply Chain Management: the Pursuit of a Consensus Definition. Journal of Business Logistics, 26, 17-25. https://doi.org/10.1002/j.2158-1592.2005.tb00203.x

[39] Amrani-Zouggar, A. (2009) Impact des contrats d'approvisionnement surla performance de la chaine logistique: Modelisation et simulation. $\mathrm{PhD}$ thesis, Bordeaux 1 .

[40] Alicke, K., Rexhausen, D. and Seyfert, A. (2017) Supply Chain 4.0 in Consumer Goods. Mckinsey \& Company.

[41] Nguyen, N.-Q., Yalaoui, F., Amodeo, L., Chehade, H. and Toggenburger, P. (2018) Electrical Vehicle Charging Coordination Algorithms Framework. In: Kahraman, C. and Kayakutlu, G., Eds., Energy Management_Collective and Computational Intelligence with Theory and Applications. Studies in Systems, Decision and Control, Springer, Cham, vol. 149, 357-373. https://doi.org/10.1007/978-3-319-75690-5 16

[42] FUJITSU (2018) Global Digital Transformation Survey, 2018 Annual Report. https://www.fujitsu.com/th/en/vision//insights/survey2/

[43] Frey, C.B. and Osborne, M.A. (2017) The Future of Employment: How Susceptible Are Jobs to Computerisation? Technological Forecasting and Social Change, 114, 254-280. https://doi.org/10.1016/j.techfore.2016.08.019

[44] Formative Content Alex Gray, Senior Writer (n.d.) The 10 Skills You Need to Thrive in the Fourth Industrial Revolution.

https://www.weforum.org/agenda/2016/01/the-10-skills-you-need-to-thrive-in-thefourth-industrial-revolution/

[45] De Carolis, A., Macchi, M., Negri, E. and Terzi, S. (2017) A Maturity Model for Assessing the Digital Readiness of Manufacturing Companies. In: Lödding, H., Riedel, R., Thoben, K.D., von Cieminski, G. and Kiritsis, D., Eds., Advances in Production Management Systems. The Path to Intelligent, Collaborative and Sustainable Manufacturing. APMS 2017. IFIP Advances in Information and Communication Technology, Springer, Cham, vol. 513, 13-20.

https://doi.org/10.1007/978-3-319-66923-6 2

[46] Schumacher, A., Erol, S. and Sihn, W. (2016) A Maturity Model for Assessing Industry 4.0 Readiness and Maturity of Manufacturing Enterprises. Procedia CIRP, 52, 161-166. https://doi.org/10.1016/j.procir.2016.07.040

[47] Leyh, C., Bley, K., Schäffer, T. and Bay, L. (2017) The Application of the Maturity Model Simmi 4.0 in Selected Enterprises.

[48] Lichtblau, K., Stich, V., Bertenrath, R., Blum, M., Bleider, M., Millack, A., Schmitt, K., Schmitz, E. and Schröter, M. (2015) Impuls-Industrie 4.0-Readiness. Impuls-Stiftung des VDMA, Aachen-Köln.

[49] Fukuyama, M. (2018) Society 5.0: Aiming for a New Human-Centered Society. Japan Spotlight, 1, 47-50.

[50] Keidanren-Japan Business Federation (2016) Toward Realization of the New Economy and Society-Reform of the Economy and Society by the Deepening of "Society 5.0 ". 